\title{
Inhibition of the integrated stress response by viral proteins that block p-elF2-elF2B association
}

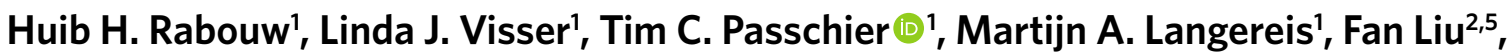 \\ Piero Giansanti ${ }^{2,6}$, Arno L. W. van Vliet', José G. Dekker', Susanne G. van der Grein', \\ Jesús G. Saucedo', Aditya A. Anand ${ }^{3}$, Mikael E. Trellet ${ }^{4}$, Alexandre M. J. J. Bonvin ${ }^{4}{ }^{4}$, Peter Walter $\mathbb{B}^{3}$, \\ Albert J. R. Heck ${ }^{\left({ }^{2}\right.}{ }^{\text {, Raoul J. de Groot }}{ }^{1,7}$ and Frank J. M. van Kuppeveld ${ }^{1,7}{ }^{1}$
}

Eukaryotic cells, when exposed to environmental or internal stress, activate the integrated stress response (ISR) to restore homeostasis and promote cell survival. Specific stress stimuli prompt dedicated stress kinases to phosphorylate eukaryotic initiation factor 2 (elF2). Phosphorylated elF2 (p-elF2) in turn sequesters the elF2-specific guanine exchange factor elF2B to block elF2 recycling, thereby halting translation initiation and reducing global protein synthesis. To circumvent stress-induced translational shutdown, viruses encode ISR antagonists. Those identified so far prevent or reverse elF2 phosphorylation. We now describe two viral proteins-one from a coronavirus and the other from a picornavirus-that have independently acquired the ability to counteract the ISR at its very core by acting as a competitive inhibitor of p-elF2-elF2B interaction. This allows continued formation of the elF2-GTP-Met-tRNAi ternary complex and unabated global translation at high p-elF2 levels that would otherwise cause translational arrest. We conclude that elF2 and p-elF2 differ in their interaction with elF2B to such effect that p-elF2-elF2B association can be selectively inhibited.

\section{T} ranslation is a fundamental, energy-intensive biosynthetic process. When exposed to a variety of environmental and internal stress conditions, eukaryotic cells switch on a regulatory pathway - the integrated stress response (ISR) - that acts at the level of translation initiation (reviewed in ref. ${ }^{1}$ ) to suppress global protein synthesis while enhancing translation of several proteins involved in cellular recovery. While primarily aimed at energy conservation, restoration of homeostasis and cell survival, the ISR will signal towards cell death under conditions of severe and unmitigated stress.

In mammalian cells, ISR signalling is initiated by any of four distinct serine/threonine kinases (that is, protein kinase R (PKR), PKR-like endoplasmic reticulum kinase (PERK), heme-regulated inhibitor (HRI) and general control non-depressible 2 (GCN2)), each of which is dedicated to sensing different types of stress stimuli. For example, PKR is triggered by cytoplasmic double-stranded RNA (dsRNA) of cellular or viral origin ${ }^{2}$. Upon detection of their respective stimulus, these proteins self-activate and phosphorylate their common target, the $\alpha$-subunit of eukaryotic initiation factor 2 (eIF2). Native, non-phosphorylated eIF2 is a heterotrimeric protein complex that associates with GTP and Met-tRNAi to form the ternary complex as a key step in translation initiation. During translation initiation, GTP is hydrolysed to GDP. Subsequently, eIF2-GDP is recycled to eIF2-GTP by the eIF2-specific guanine exchange factor (GEF) eIF2 ${ }^{3}$. Phosphorylated eIF2 (p-eIF2) interferes with eIF2-GDP/GTP exchange by stably interacting with eIF2B ${ }^{4}$. As cellular concentrations of eIF2 greatly exceed those of eIF $2 \mathrm{~B}^{5,6}$, even modest levels of p-eIF2 suffice to effectively inhibit eIF2B function? causing ternary complex levels to drop and translation to halt.

ISR-induced downregulation of virus protein synthesis is an effective antiviral defence mechanism. Many viruses encode antagonistic proteins that allow them to evade or divert the detrimental consequences of the ISR. These viral ISR antagonists fall into different groups. Class 1 antagonists, such as influenza A virus NS1 (ref. ${ }^{8}$ ) and Middle East respiratory syndrome coronavirus $4 \mathrm{a}^{9}$, avert eIF2 kinase activation; for example, by sequestering or degrading the stressor. In contrast, class 2 antagonists, such as vaccinia virus $\mathrm{K} 3 \mathrm{~L}^{10,11}$, prevent eIF2 phosphorylation by binding and inhibiting the function of the (activated) sensor. Finally, class 3 antagonists, such as herpes simplex virus ICP34.5 and alphacoronavirus p7, induce dephosphorylation of eIF2 $\alpha$ by recruiting the cellular phosphatase PP1 (refs. 12,13). In a search for other types of ISR antagonist, we focused on coronaviruses-a group of positive-strand RNA viruses of exceptional genetic complexity. In addition to a strictly conserved set of structural and non-structural proteins, coronaviruses encode a wide variety of accessory proteins that are genus, clade or species specific. One of these-the open reading frame 10 (ORF10)-encoded accessory protein (AcP10) of beluga whale coronavirus (Bw-CoV) SW1-attracted our attention because of its sequence similarity to cellular uridine cytidine kinases $(\mathrm{UCKs})^{14}$. Here, we show that AcP10, while retaining UCK activity, also has a UCK-independent function as an ISR antagonist. We demonstrate that AcP10 differs in its mode of action from all other viral ISR antagonists described so far and counteracts the ISR at its core

\footnotetext{
'Virology Division, Department of Infectious Diseases and Immunology, Faculty of Veterinary Medicine, Utrecht University, Utrecht, the Netherlands. ${ }^{2}$ Biomolecular Mass Spectrometry and Proteomics, Utrecht Institute for Pharmaceutical Sciences and Bijvoet Centre for Biomolecular Research, Utrecht University, Utrecht, the Netherlands. ${ }^{3}$ Howard Hughes Medical Institute and Department of Biochemistry and Biophysics, University of California at San Francisco, San Francisco, CA, USA. 'Bijvoet Center for Biomolecular Research, Faculty of Science, Utrecht University, Utrecht, the Netherlands. ${ }^{5}$ Present address: Department of Chemical Biology, Leibniz-Forschungsinstitut für Molekulare Pharmakologie, Berlin, Germany. ${ }^{6}$ Present address: Chair of Proteomics and Bioanalytics, Technical University of Munich, Freising, Germany. ${ }^{7}$ These authors jointly supervised this work: Raoul J. de Groot, Frank J. M. van Kuppeveld. 凶e-mail: f.j.m.vankuppeveld@uu.nl
} 
by acting as a competitive inhibitor of the p-eIF2-eIF2B interaction. AcP10 thereby allows ternary complex formation and translation to proceed unimpaired even at very high levels of p-eIF2. Furthermore, this ISR evasion strategy is not exclusive to $\mathrm{Bw}-\mathrm{CoV}$, as we show that Aichivirus ( $\mathrm{AiV}$; genus Kobuvirus) - a human gastroenteric picornavirus-encodes a protein (AiVL) that blocks the ISR via a mechanism similar to that of AcP10. Using a recombinant $\mathrm{AiV}$ with a defective $\mathrm{L}$ gene, we show that $\mathrm{AiVL}$ acts as ISR antagonist also in the natural context of AiV-infected cells, where this function is essential for optimum virus propagation.

\section{Results}

AcP10 is a uridine kinase and an ISR antagonist. AcP10 is encoded by one of eight accessory genes found in Bw-CoV SW 1 and related viruses in bottlenose dolphins (for a schematic representation of the 31.7-kilobase viral genome, see Fig. 1a). In accordance with its sequence similarity to cellular UCKs (Fig. 1b,c), recombinant AcP10 catalysed the ATP-dependent conversion of uridine into UMP in vitro (Fig. 1d). This enzymatic activity was lost upon substitution of residues in the predicted catalytic and ATP-binding sites (Asp 41 to Ala or Lys 16 to Asn, respectively) that are strictly conserved among cellular UCKs and critical for their function. Thus, AcP10 was unambiguously identified as a uridine kinase. Remarkably, however, AcP10 has an additional function as an ISR antagonist, as we discovered in transient expression experiments. We and others previously reported that transfection of HeLa cells with enhanced green fluorescent protein plasmids (pEGFPs) triggers the ISR via dsRNA-dependent activation of PKR resulting in the formation of stress granules ${ }^{9,15,16}$. Activation can be blocked by the expression of dsRNA-binding ISR antagonists, such as influenza virus NS1 and Middle East respiratory syndrome coronavirus $\mathrm{p} 4 \mathrm{a}^{9}$. Surprisingly, cells expressing AcP10-EGFP were consistently devoid of stress granules (Fig. 1f, left), providing an indication that AcP10 counteracts the ISR.

To test whether AcP10, like NS1, acts in a PKR-specific manner, transfected cells were treated with arsenite, to induce the ISR also via HRI. Under these conditions, AcP10-but not NS1-prevented stress granule formation (Fig. 1f, middle). However, AcP10 did not block stress granule production in cells treated with the ISR-independent translation inhibitor pateamine A (Fig. 1f, right). The data thus suggest that AcP10 targets the ISR downstream of the eIF $2 \alpha$ kinases. This function is UCK independent, because UCK-deficient AcP10 mutants still suppressed stress granule formation (Fig. 1g). To identify AcP10 residues that are critical to ISR inhibition, we performed alanine screening on a selection of histidines and potentially phosphorylated serines and threonines (16 in total), all surface exposed in the UCK fold (for a predicted three-dimensional structure, see Extended Data Fig. 1). Of the mutants tested, AcP10 $10^{\mathrm{H} 193 \mathrm{~A}}, \mathrm{AcP} 10^{\mathrm{H} 200 \mathrm{~A}}$ and the double mutant
AcP10 ${ }^{\mathrm{H} 193 \mathrm{~A} / \mathrm{H} 200 \mathrm{~A}}$ (henceforth called AcP10(SA-)) no longer suppressed the formation of stress granules (Fig. 1g). However, they still exhibited uridine kinase activity (Fig. 1e), demonstrating that the ISR inhibitor and UCK functions of AcP10 are separable and hence independent.

Consistent with a role as UCK and ISR antagonist, AcP10-EGFP localized to the cytosol. However, we did note that the protein largely accumulated in perinuclear deposits, apparently in aggregated form (Fig. 1f,g). Indeed, upon fractionation of Triton X-100 lysates of transfected cells, most AcP10 was insoluble and resided in the pellet with only about $20 \%$ remaining in the supernatant (Extended Data Fig. 2). Importantly, stress granule formation was also blocked in cells that expressed AcP10-EGFP at very low levels, and those that lacked AcP10 deposits (see also Extended Data Fig. 3b). The aggregation of AcP10-EGFP at high intracellular concentrations thus appears irrelevant to ISR inhibition. In addition, the inactive mutant $\mathrm{AcP} 10(\mathrm{SA}-)$ also accumulated in aggregates, indicating that the presence of perinuclear deposits per se does not interfere with stress granule formation.

AcP10 rescues global translation in the presence of p-eIF2. As AcP10's ability to inhibit the ISR is not specific for a particular eIF2 kinase nor type of stressor, we assessed whether AcP10 induces eIF2 dephosphorylation (class 3 antagonist) by analysing its impact on p-eIF $2 \alpha$ levels in stressed cells.

Cells dually stressed by DNA transfection and arsenite treatment had high levels of p-eIF2 $\alpha$ compared with non-stressed cells, and global translation was markedly reduced, as measured by western blot detection of puromycin incorporation (Fig. 2a). AcP10 did not affect eIF2 phosphorylation, as p-eIF2 $\alpha$ levels in AcP10-expressing cell populations were identical to those in the controls. Nevertheless, AcP10 efficiently rescued global protein synthesis. Translation was also restored by UCK-deficient AcP $10^{\mathrm{D} 41 \mathrm{~A}}$ but not by AcP10(SA-) or NS1. Of note, the analyses were performed on total cell populations in which only $30-50 \%$ of the cells produced AcP10. To quantitatively assess to what extent AcP10 rescues translation during stress, global protein synthesis was measured in individual cells by flow cytometry. In cells stressed by DNA transfection exclusively (Fig. 2b) or by a combination of transfection and arsenite treatment (Extended Data Fig. 3a), AcP10 allowed protein synthesis to proceed unhindered at rates indistinguishable from those in non-stressed cells. Notably, minute amounts of AcP10, barely detectable by fluorescence microscopy or flow cytometry, sufficed to block stress granule formation (Extended Data Fig. 3b) and to fully rescue translation (Extended Data Fig. 3c).

Unfortunately, we were unable to study the role of AcP10 in cells infected with Bw-CoV SW1, as this virus has not yet been isolated in cultured cells and, hence, no reverse genetics system has been established. To investigate whether AcP10 also inhibits the ISR

Fig. 1 | AcP10 is a uridine kinase and an ISR antagonist. a, Schematic of the Bw-CoV genome and the ORF10-encoded protein AcP10. b, Alignment of AcP10 with human UCK2 (hUCK2). The ATP-binding domain (consensus sequence; GXXXXGKS) and the (putative) catalytic aspartic acid are indicated. c, Phylogenetic tree of uridine kinases originating from various branches of the tree of life, including a structurally related distant relative of uridine kinases (pantothenate kinase (PANK)) as an outgroup ${ }^{58}$. The scale bar indicates the number of amino acid differences between sequences. A full list of the protein sequences used for this analysis is given in the source data file for this figure. $\mathbf{d}$, Thin-layer chromatography analysis of an in vitro uridine kinase assay using the indicated proteins. Highlighted are the positions of the substrates (ATP and $U$ ) and end products (ADP and UMP) of the uridine kinase reaction. $\mathbf{e}$, Thin-layer chromatography analysis of an in vitro uridine kinase assay using AcP10 mutants that lack the ability to antagonize the ISR. f, Immunofluorescence analysis of stress granule (SG) formation in HeLa cells transiently overexpressing the indicated EGFP fusion proteins, without additional treatment (PKR-dependent plasmid DNA-induced stress), after treatment with $500 \mu \mathrm{M}$ arsenite for 45 min (HRI-dependent stress) or after treatment with $100 \mathrm{nM}$ pateamine A (pat. A) for $2 \mathrm{~h}$ (elF $2 \alpha$-independent stress). EGFP expression is shown in green, whereas the stress granule marker G3BP1 is shown in red. $\mathbf{g}$, Immunofluorescence analysis of stress granule formation in arsenite-treated HeLa cells transiently overexpressing the indicated EGFP fusion proteins. K16N (ATP-binding pocket) and D41A (catalytic residue) mutations in AcP10 abolish its uridine kinase activity, whereas H193A and H200A mutations abolish AcP10's ability to block the ISR. In $\mathbf{f}$ and $\mathbf{g}$ : scale bars, $50 \mu \mathrm{m}$; quantifications of the percentages of stress granule-positive cells are given in the bar graph to the right; statistical analysis was assessed using one-way analysis of variance (ANOVA) with a Bonferroni post-hoc test; and data represent means \pm s.d. of $n=3$ biologically independent experiments. NS, not significant. 
in virus-infected cells, we resorted to a model based on recombinant encephalomyocarditis virus mutant EMCV- $\mathrm{L}^{\mathrm{zn}}$, in which the autologous ISR antagonist (the leader (L) protein) is inactivated. Consequently, the mutant virus can no longer counteract the ISR ${ }^{17}$; thus, it can be used as a convenient platform for the identification and characterization of ISR antagonists of other viruses ${ }^{9,18}$. Infection with EMCV-L $\mathrm{L}^{\mathrm{zn}}$, EMCV-L $\mathrm{L}^{\mathrm{zn}}-\mathrm{AcP} 10$ or EMCV-L ${ }^{\mathrm{zn}}-\mathrm{AcP} 10(\mathrm{SA}-)$ (Extended Data Fig. 4) induced eIF2 $\alpha$ phosphorylation to similar
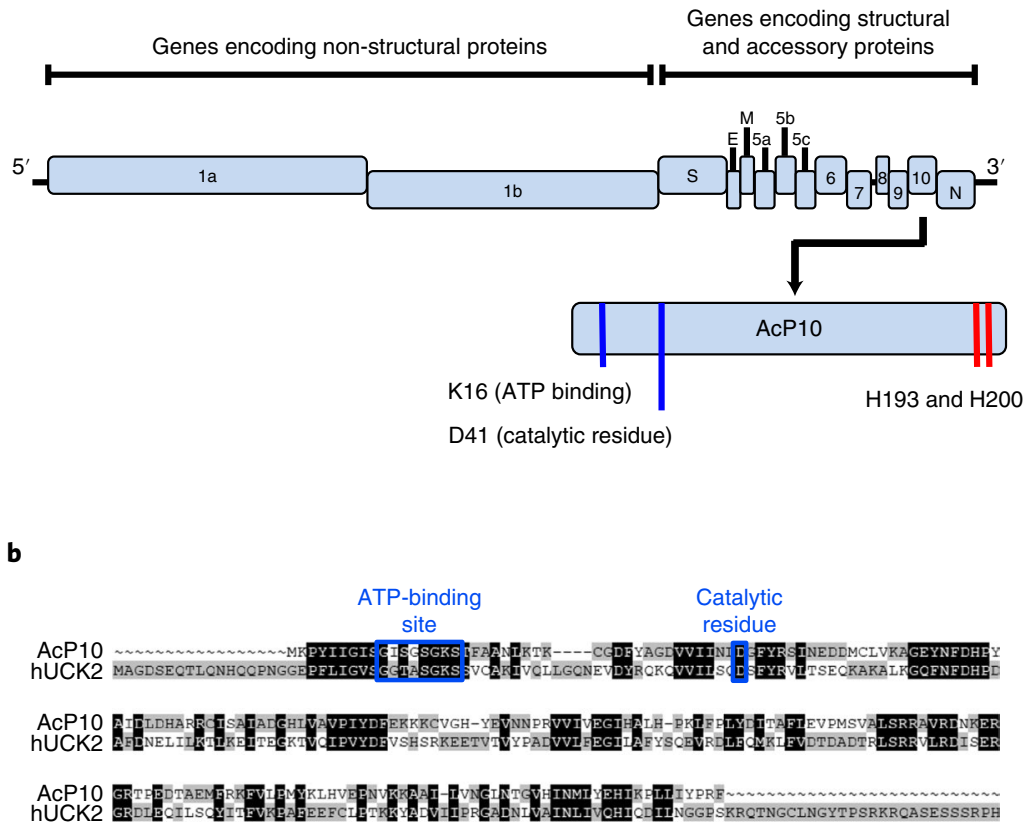
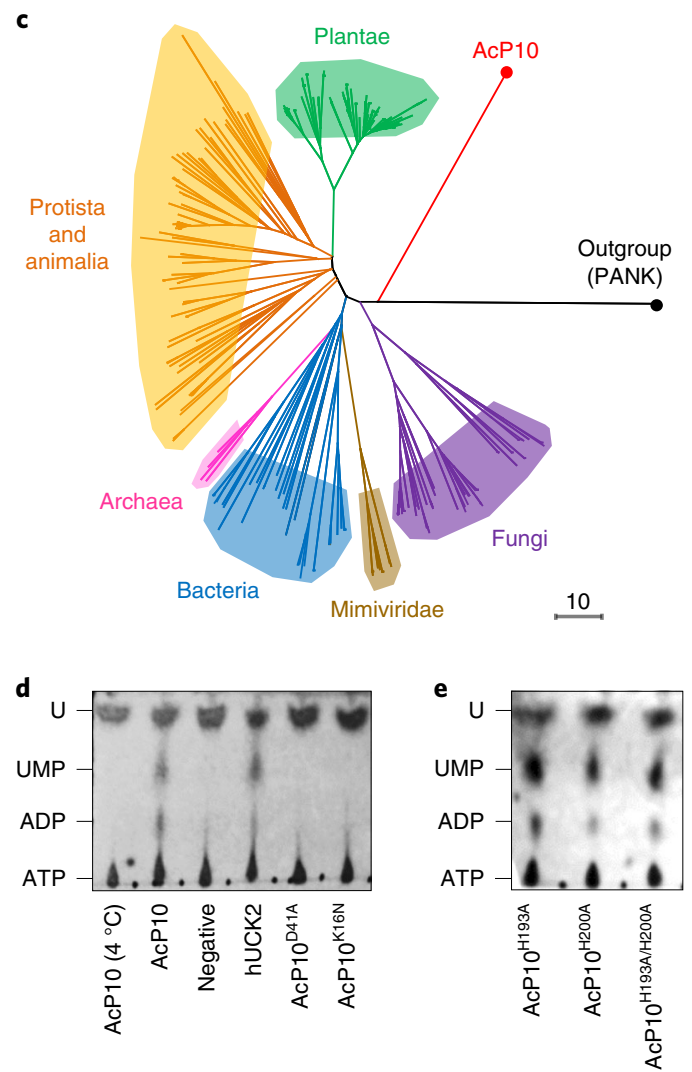

f

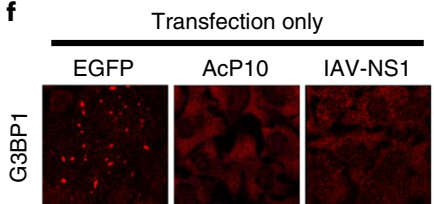

品
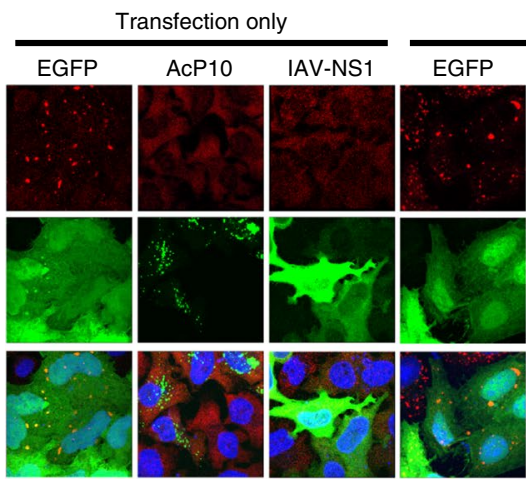

+ Arsenite
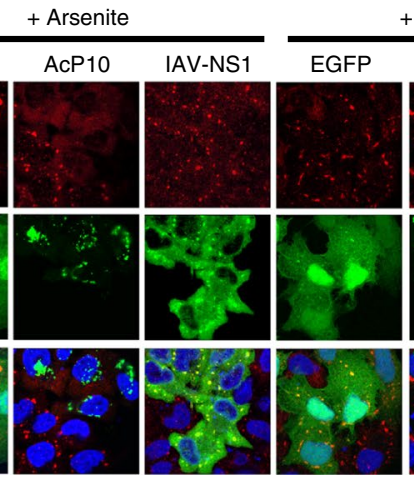

+ Pateamine $A$

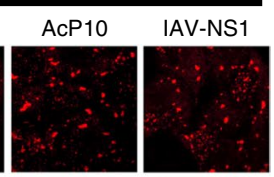

g

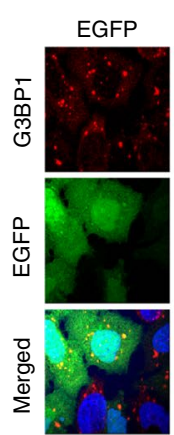

+ Arsenite
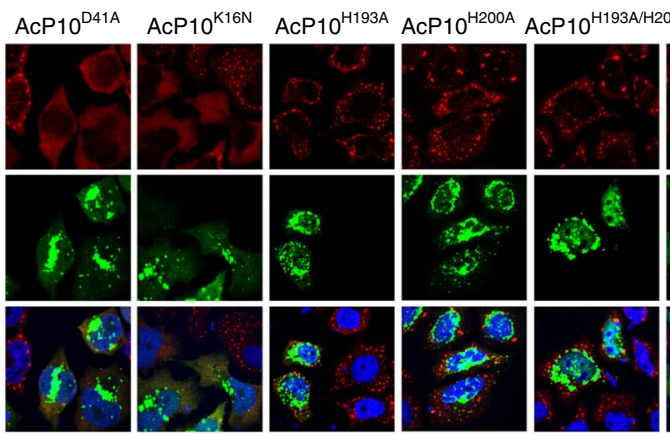
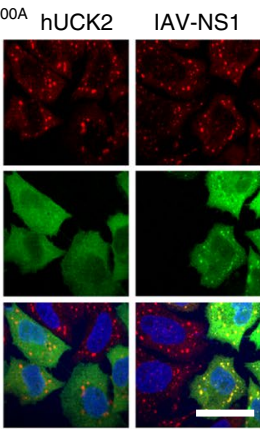
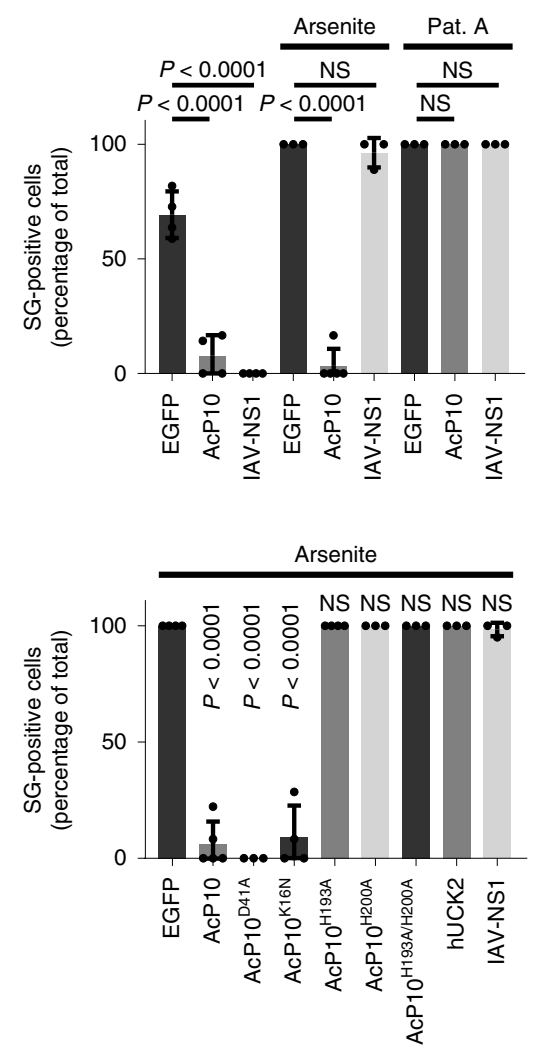


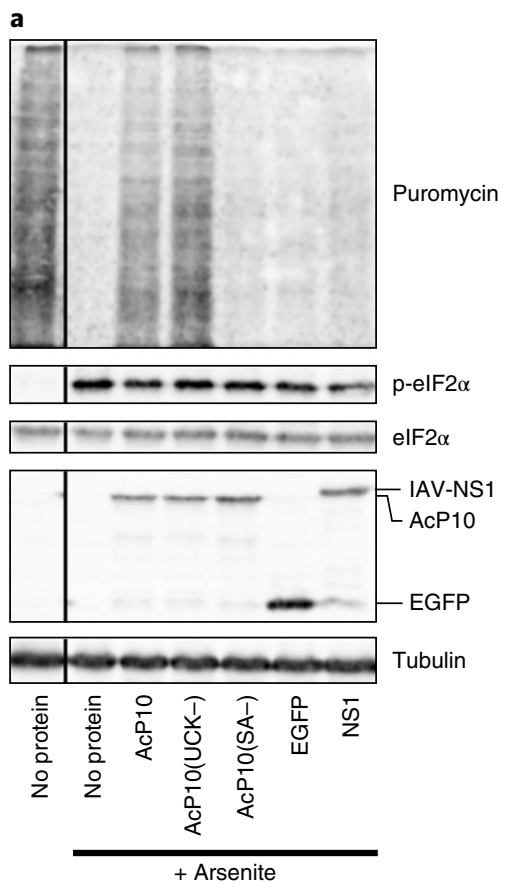

b
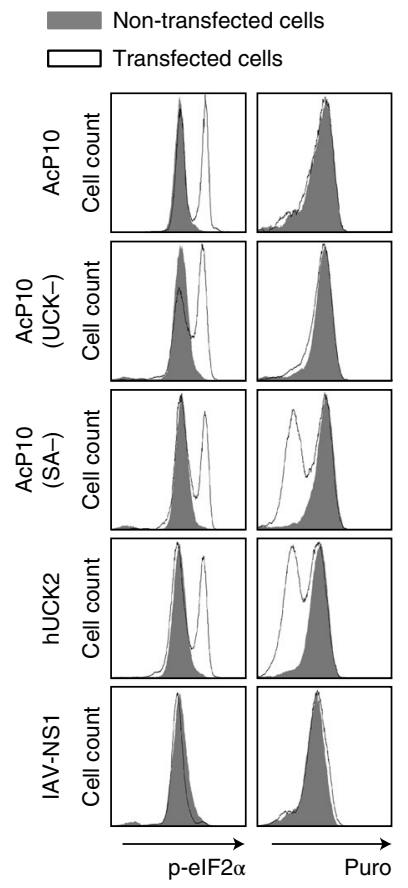

c

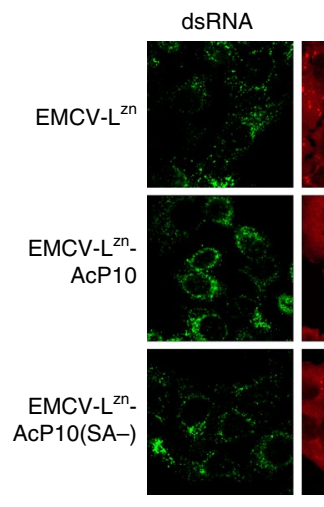

elF3
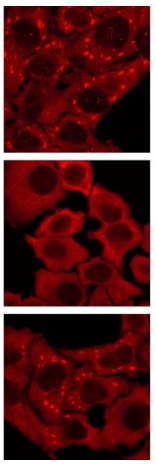

G3BP1

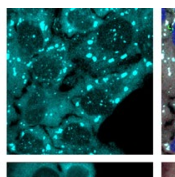

Merged
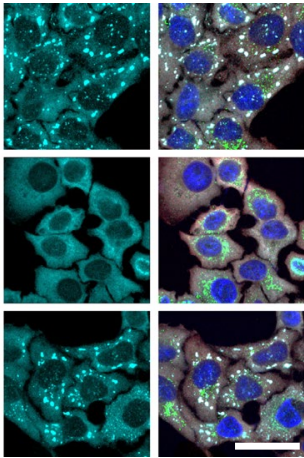

d

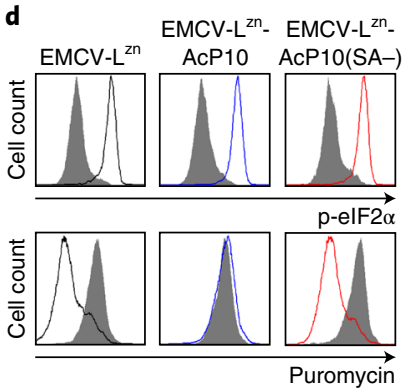

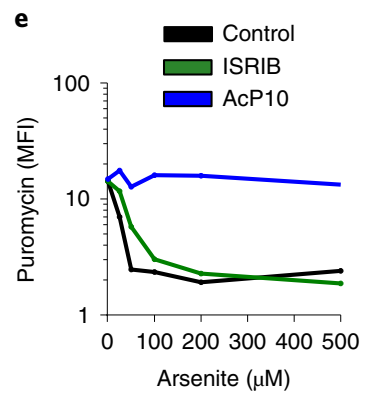

Fig. 2 | AcP10 rescues global translation in the presence of p-elF2. a, Western blot analysis of p-elF2 $\alpha$ levels and translation rates, as labelled by puromycin treatment for $15 \mathrm{~min}^{59}$, in cells expressing the indicated EGFP fusion proteins and treated with $500 \mu \mathrm{M}$ arsenite for $45 \mathrm{~min}$. AcP10 mutants lacking the stress antagonist function ( $\mathrm{AcP} 10^{\mathrm{H} 193 \mathrm{~A} / \mathrm{H} 200 \mathrm{~A}}$ ) or UCK function ( $\mathrm{AcP} 10^{\mathrm{D} 4 \mathrm{~A}}$ ) are indicated as $\mathrm{AcP} 10(\mathrm{SA}-$ ) and $\mathrm{ACP}(\mathrm{UCK}-$ ), respectively. b. Flow cytometry analysis of p-elF2 $\alpha$ levels (left) and active translation (right) in cells transiently transfected with plasmids encoding the indicated proteins. Transfected cells were identified based on EGFP signal. Non-transfected cells (indicated in grey) from the same wells served as internal controls. c, The AcP10 or AcP10(SA-) gene was inserted into the genome of a picornavirus that efficiently induces ISR activation $\left(E M C V-L^{2 n}\right)$. Cells were infected $(\mathrm{MOI}=2)$ with the indicated recombinant viruses and stress granule formation was monitored at $5 \mathrm{~h}$ post-infection by immunofluorescence. dsRNA synthesis was used as a marker for virus replication, and the stress granule markers elF3 and G3BP1 were visualized to assess stress granule formation. Scale bar, $50 \mu \mathrm{m}$. d, HeLa cells were infected $(\mathrm{MOI}=5)$ with the indicated recombinant viruses. Shown is a flow cytometry analysis of p-elF2 $\alpha$ levels (top) and active translation (bottom) at $5 \mathrm{~h}$ post-infection, relative to uninfected control cells (grey fill). e, Direct comparison of ISR inhibition by the elF2B binders AcP10 and ISRIB. Shown are the translation rates, as determined by flow cytometry analysis, in mock-treated cells, cells treated with $200 \mathrm{nM}$ ISRIB and cells overexpressing AcP10, in the presence of different concentrations of arsenite. MFI, mean fluorescence intensity.

extents. However, only cells infected with EMCV-L $\mathrm{L}^{\mathrm{zn}}-\mathrm{AcP} 10$ were devoid of stress granules (Fig. 2c) and displayed translation rates similar as those in non-infected cells (Fig. 2d). These observations provide formal evidence that AcP10 also counters the ISR in virus-infected cells.

Recently, a small molecule inhibitor of the ISR (ISRIB) was described to render cells less sensitive to p-eIF2. ISRIB promotes the assembly of the fully active decameric eIF2B complex, and thereby increases eIF2B GEF activity ${ }^{19-22}$. However, ISRIB does not prevent p-eIF2 from binding eIF2B and thus cannot counteract the ISR at high intracellular p-eIF2 concentrations that sequester virtually all eIF2B. For this reason, ISRIB fails to rescue translation in $\mathrm{HeLa}$ cells treated with arsenite concentrations $>100 \mu \mathrm{M}^{23}$, even at high ISRIB concentrations $(200 \mathrm{nM}$, which is 40 times ISRIB's reported half-maximum effective concentration ${ }^{20}$ ). In contrast with ISRIB, AcP10 remained fully active even in cells exposed to arsenite concentrations of up to $500 \mu \mathrm{M}$ (Fig. 2e). The combined data suggest that AcP10 blocks the ISR downstream of eIF2 $\alpha$ phosphorylation, not by any mechanism previously described for other viral ISR antagonists or ISRIB, but by allowing global translation to proceed seemingly unimpaired even at high intracellular concentrations of p-eIF $2 \alpha$.

AcP10 prevents upstream ORF (uORF)-mediated translation upregulation in stressed cells. While global translation rates decline in stressed cells, the production of a subset of proteins is promoted. Among these proteins is activating transcription factor 4 (ATF4) - a key effector of the ISR. Its synthesis is under the control of a cis-acting messenger RNA (mRNA) regulatory element, which comprises two upstream ORFs (uORF1 and uORF2). The regulatory mechanism is based on cap-dependent translation of uORF1 with resumed scanning of $40 \mathrm{~S}$ ribosomes and re-initiation at downstream start codons dependent on the rate of ternary complex formation and recruitment. At physiological ternary complex concentrations, re-initiation preferentially occurs at uORF2, preventing ATF4 expression. However, when ternary complex concentrations drop, the ribosomes bypass the uORF2 AUG codon and ATF4 expression is switched on. Predictably, when ternary complex concentrations fall even further, the ATF4 AUG codon is also bypassed causing ATF4 expression to be switched off again ${ }^{24-26}$. To study whether AcP10 affects uORF-mediated translation regulation under conditions of stress, an expression vector was constructed encoding EGFP under control of the ATF4 regulatory element (Fig. 3a). EGFP expression was measured in cells under conditions of increasing stress, and the effect of AcP10 co-expression was assessed with the inactive mutant $\mathrm{AcP} 10(\mathrm{SA}-)$ serving as a negative control. In accordance with our observations for global protein synthesis, translation from a control reporter construct lacking the ATF4 regulatory element was salvaged by wild-type AcP10 even under conditions of extreme stress, but was inhibited in stressed cells 

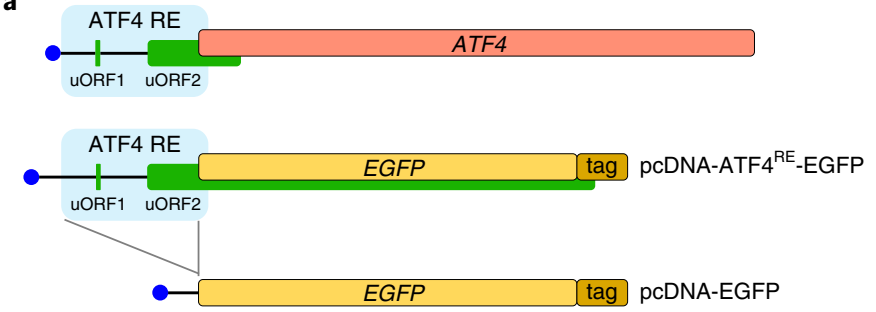

b
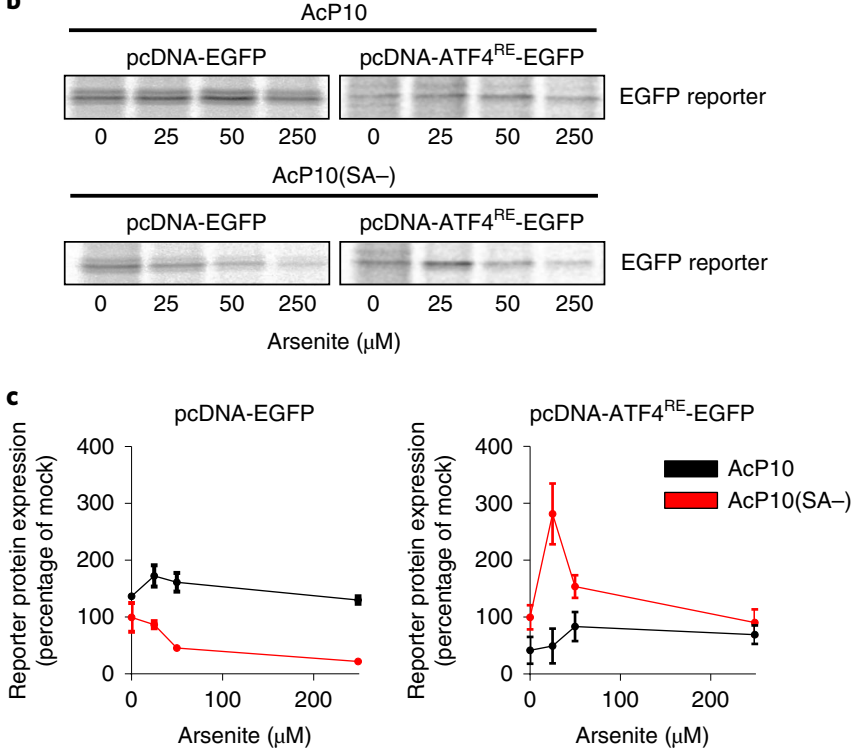

Fig. 3 | AcP10 prevents uORF-mediated translation upregulation in stressed cells. a, Schematic of the cellular ATF4 mRNA (top) and the mRNAs encoded by the ATF4 reporter construct (middle) or the control reporter construct lacking the ATF4 regulatory element (RE) (bottom). The cap structure is indicated in blue and the ATF4 uORFs are indicated in green. The ATF4 gene and EGFP reporter gene are indicated in orange and yellow, respectively. b, HeLa PKR ${ }^{\mathrm{KO}}$ cells were co-transfected with plasmids encoding AcP10 or AcP10(SA-) and the plasmids encoding Strep-tagged EGFP reporter protein shown in a. Cells were treated with the indicated arsenite concentrations for $30 \mathrm{~min}$ and the reporter protein was pulse labelled by ${ }^{35} \mathrm{~S}$ Met/Cys incorporation for an additional $90 \mathrm{~min}$. Strep-tagged EGFP was purified from cell lysates and separated with SDS-PAGE. The presence of radioactive labelling was determined using a phosphorimager. c, Quantification of $n=2$ biologically independent reporter protein ${ }^{35} \mathrm{~S}$ Met/Cys incorporation experiments, as shown in $\mathbf{b}$. Reporter protein expression levels (means \pm s.d.) are shown relative to those in untreated cells expressing AcP10(SA-).

expressing AcP10(SA-) (Fig. 3b,c). Conversely, EGFP expression under control of the ATF4 regulatory element was upregulated in AcP10(SA-)-producing cells, albeit only when exposed to moderate stress $(25 \mu \mathrm{M}$ arsenite) (Fig. 3c, right). Importantly, under identical conditions, this upregulation did not occur in AcP10-expressing cells. These data suggest that AcP10 allows formation of ternary complexes to proceed, irrespective of the p-eIF2 concentrations.

eIF2B is a cellular interaction partner of AcP10. To determine how AcP10 renders cells resistant to p-eIF $2 \alpha$ and maintains ternary complex concentrations at sufficient levels to allow unperturbed translation, its cellular interaction partners were identified by tandem affinity purification (TAP) mass spectrometry (see Methods for experimental details). Figure 4a shows a STRING (Search Tool for the Retrieval of Interacting Genes/Proteins) analysis of all proteins that were two- to fivefold, five- to tenfold or greater than tenfold enriched in peptide spectral matches (PSMs) in the AcP10 sample compared with each of the controls, using a threshold of at least 25 PSMs detected. SAINT probability scores ${ }^{27}$ and fold enrichment in spectral counts as calculated relative to the negative control (foot-and-mouth disease virus leader proteinase) are shown in Fig. 4b. Importantly, among the hits with the highest PSM enrichment factors were all three subunits of eIF2 (eIF2 $\alpha$, eIF2 $\beta$ and eIF $2 \gamma)$ and all five subunits of eIF2B (eIF2B $\alpha$, eIF2B $\beta$, eIF2B $\gamma$, eIF2B $\delta$ and eIF2Be) (see also Supplementary Table 1). Since the eIF2B subunits of humans and beluga whales are $92-96 \%$ identical, AcP10 probably has the same interaction, and consequently function, in its natural host.

The interaction of AcP10 with eIF2 and eIF2B was confirmed by western blot analysis using antibodies directed against eIF2B $\varepsilon$ (representing the eIF2B complex) and eIF2 $\alpha$ (representing the eIF2 complex) (Fig. 4c). Notably, yeast eIF2 was shown to stably interact with eIF2B under the conditions used in these pull-down experiments, but to dissociate from eIF2B under high-salt conditions ${ }^{28}$. To determine whether AcP10 binds eIF2, eIF2B or the eIF2-eIF2B macrocomplex, the pull-down samples were subjected to high-salt elution to disrupt eIF2-eIF2B interaction ${ }^{28}$. While most eIF2 $\alpha$ ended up in the supernatant fraction (Fig. 4c; lanes marked 'sup.), eIF2B $\varepsilon$ remained AcP10 associated (Fig. 4c; lanes marked 'beads'). To corroborate the observations and to gain further insight into how AcP10 associates with eIF2B, AcP10 affinity pull-down samples purified from HEK293T cell lysates were subjected to lysine-specific chemical cross-linking and mass spectrometry analysis using described procedures $^{29}$. Of the 86 cross-linked dipeptides that were identified, most were intra-links within AcP10 or eIF2B. However, six of them involved a linkage of AcP10 to eIF2B $(n=2)$ or eIF2B $(n=4)$. One additional dipeptide arose from a cross-link between the amino (N)-terminal S-tag of AcP10 and eIF2Be (Extended Data Fig. 5). Collectively, the data suggest that AcP10 binds directly to eIF2B, and that eIF2 is co-purified in AcP10-eIF2B complexes owing to its association with eIF2B.

eIF2B preferentially binds eIF2 over p-eIF2 in the presence of AcP10. AcP10 renders eIF2B insensitive to p-eIF2 in stressed cells but does not noticeably affect translation in non-stressed cells. The data therefore suggest that AcP10 affects the interaction of eIF2B with p-eIF2, but not with eIF2. The fact that eIF2, through its association with eIF2B, co-purifies with the AcP10-eIF2B complex (Fig. 4c) provided an experimental approach to study the impact of AcP10 on the interaction of eIF2B with eIF2 and p-eIF2. AcP10eIF2B complexes were isolated from HEK293T cells transiently expressing TAP-tagged AcP10 and stressed by exposure to arsenite concentrations of up to $500 \mu \mathrm{M}$. Strikingly, even under conditions of severe stress (Fig. 5a; 'total lysate'; $500 \mu \mathrm{M}$ arsenite), AcP10-eIF2B complexes were devoid of detectable p-eIF2 (Fig. 5a; 'TAP tag'). These data suggest that eIF2 associated with AcP10-eIF2B is in its non-phosphorylated form and that AcP10 precludes the p-eIF2eIF2B interaction in stressed cells.

For independent confirmation of these observations, we performed the reciprocal experiment entailing a pull-down analysis targeting eIF2B instead of AcP10. HeLa cells stably expressing FLAG-tagged eIF2B $\beta^{30}$ were transfected to transiently express EGFP-tagged AcP10 or AcP10(SA-) and either left untreated or stressed using $500 \mu \mathrm{M}$ arsenite. eIF2B complexes and associated proteins were purified by FLAG-tag chromatography, and amounts of co-purified eIF2 $\alpha$, p-eIF $2 \alpha$ and AcP10 were assessed (Fig. 5b). In stressed cell cultures expressing AcP10, eIF2B macrocomplexes contained $70 \%$ less p-eIF2 than in stressed cell cultures expressing AcP10(SA-). Since this reduction was achieved within a cell population in which $70 \%$ of the cells expressed AcP10 (Fig. $5 c$ ), this finding suggests that very little, if any, p-eIF2 binds to eIF2B 
a
AcP10 versus control enrichment

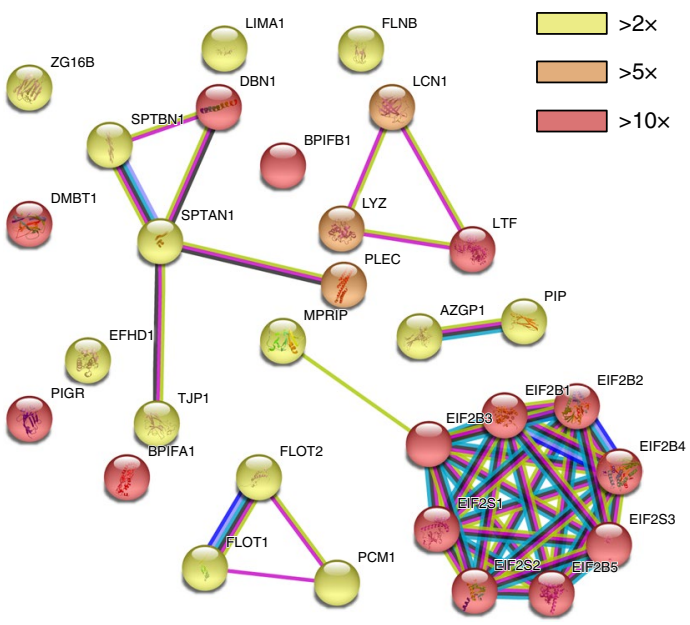

c

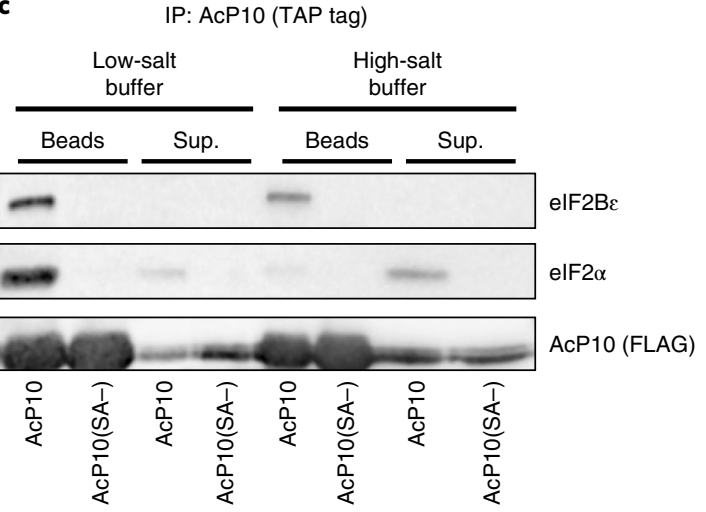

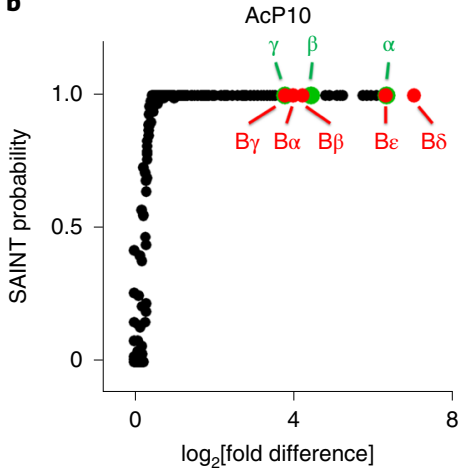

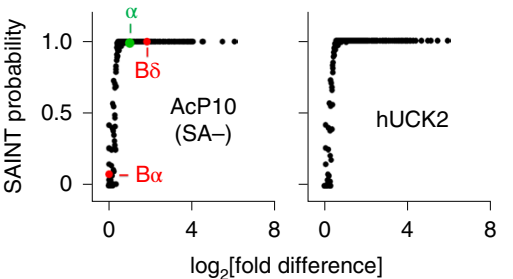

Fig. 4 I elF2B is a cellular interaction partner of AcP10. a, TAP-tagged AcP10 was transiently overexpressed in and purified from HEK293T cells. Co-purified cellular interaction partners were analysed by mass spectrometry. Shown is a STRING interactome analysis of the proteins that were found to be co-enriched with AcP10, relative to each of the controls, by two- to fivefold (yellow), five- to tenfold (orange) or greater than tenfold (red), with a threshold of at least 25 PSMs detected per protein (see also Supplementary Table 1 and the source data for this figure). b, Graphs showing SAINT

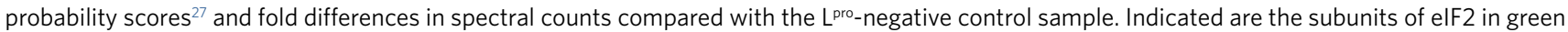
and elF2B in red. These subunits all show a very confident SAINT score ( $>0.98$ ) and fold change in the AcP10 pull-down (top) but not in the two controls (bottom). Proteins with a $\log _{2}$ [fold difference] $<0$ are considered background and were therefore discarded from the analysis. c, TAP-tagged AcP10 or AcP10(SA-) was purified from HEK293T cells. Subsequently, beads were incubated for 5 min in standard wash buffer versus high-salt buffer (500 mM $\mathrm{KCl}$ ) to dissociate elF2 from elF2B ${ }^{28}$. Supernatant fractions (sup.) and bead fractions were analysed by western blot for the presence of elF2 (represented by elF2 $\alpha$ ) and elF2B (represented by elF2B $\varepsilon$ ).

in AcP10-expressing cells. The results strongly support the notion that AcP10, through its association with eIF2B, selectively hampers p-eIF2-eIF2B interaction and thereby promotes continued eIF2B-mediated eIF2-GDP/GTP exchange, ternary complex formation and translation. The data also provide an indication of the AcP10 mechanism. In TAP-tagged purified AcP10-eIF2B complexes, the amounts of associated eIF2B (Fig. 5a, right) consistently declined with increasing intracellular levels of p-eIF2 (Fig. 5a, left). This finding strongly supports a mechanism of competitive binding. Additional support comes from experiments that revealed an association also between AcP10(SA-) and eIF2B in non-stressed cells, but not in stressed cells (Fig. 5b). Apparently, the mutations in $\mathrm{AcP} 10(\mathrm{SA}-)$ reduce its binding affinity for eIF2B rather than prevent binding altogether, explaining why eIF2B was lost during protracted $(20 \mathrm{~h})$, multistep TAP-tag purification (Fig. 5a) but not during the relatively rapid $(3 \mathrm{~h})$, one-step FLAG-tag isolation procedure. Importantly, eIF2B purified from stressed cells was associated with large quantities of p-eIF2 but no AcP10(SA-). The data suggest that, as a consequence of its reduced affinity, AcP10(SA-) is displaced from eIF2B by p-eIF2 more readily than wild-type AcP10, again consistent with competitive binding. From the combined results, we conclude that AcP10 salvages global translation in stressed cells in the face of ISR activation by acting as a competitive inhibitor of p-eIF2-eIF2B association. This competition may be achieved by overlapping binding sites of AcP10 and p-eIF2 on eIF2B. Alternatively, the AcP10-eIF2B interaction may lock eIF2B in a conformation that does not allow p-eIF2 binding and vice versa.

The $\mathrm{L}$ protein of the picornavirus $\mathrm{AiV}$ inhibits the ISR via an AcP10-like mechanism. AcP10 inhibits the ISR via a mechanism that to the best of our knowledge has not been described before. This prompted the question of whether other viruses, unrelated to Bw-CoV, might encode stress inhibitors with a similar mechanism. To study this, we focused on L proteins encoded by picornaviruses. Like the coronavirus accessory proteins, picornavirus L proteins are generally dispensable for virus replication in vitro and highly diverse 


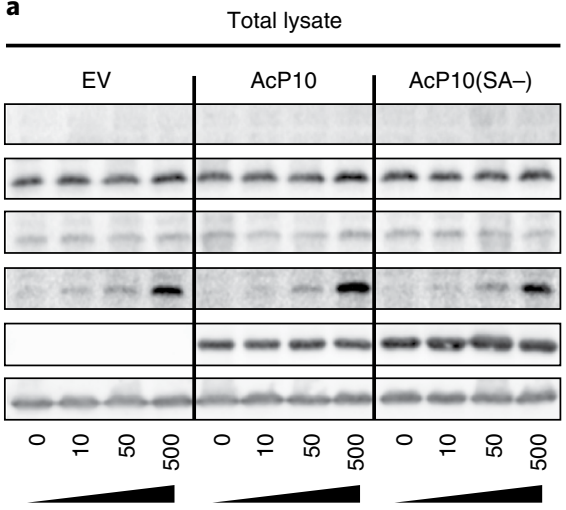

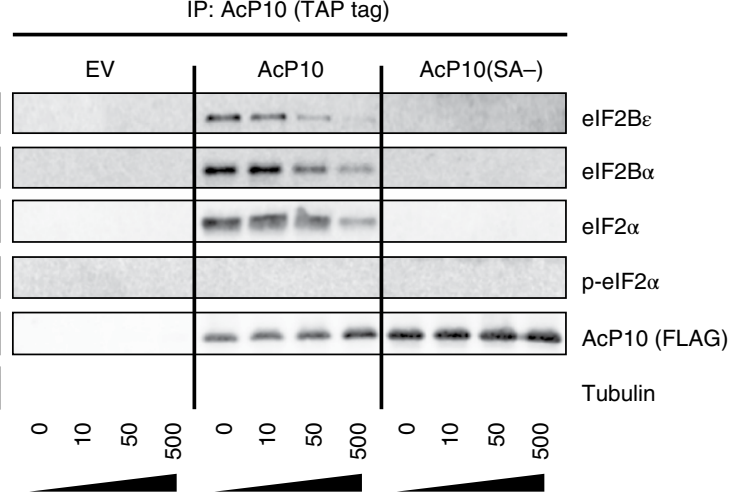

Arsenite $(\mu \mathrm{M})$

b

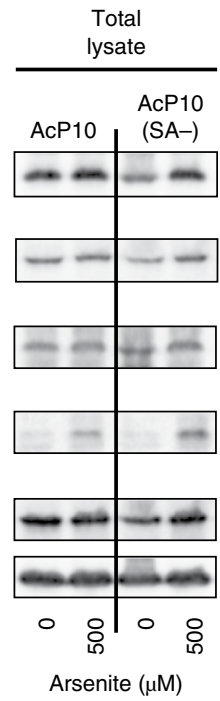

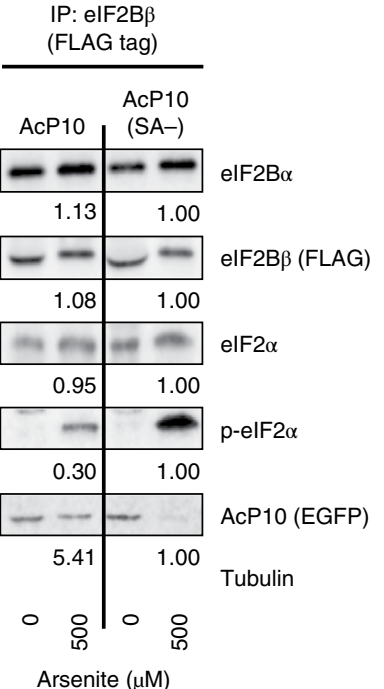

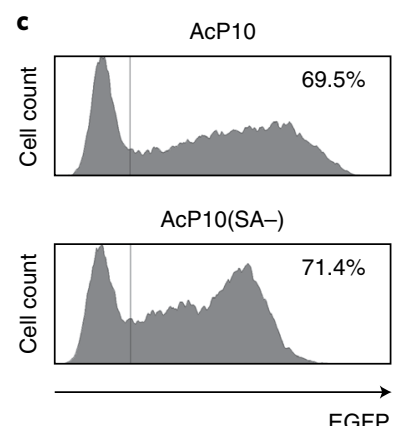

Fig. 5 | elF2B preferentially binds elF2 over p-elF2 in the presence of AcP10. $\mathbf{a}$, The indicated TAP-tagged proteins were transiently overexpressed in HEK293T cells. After treatment with the indicated arsenite concentrations for $1 \mathrm{~h}$, they were purified from cell lysates. Associations of elF2B, elF2 and/or p-elF2 with AcP10 were analysed by western blot using antibodies directed against elF2B $\alpha$, elF2B $\varepsilon$, elF2 $\alpha$ and p-elF2 $\alpha$, respectively. b, HeLa cells stably expressing endogenous levels of $3 \times \mathrm{FLAG}$-tagged elF2B $\beta^{30}$ were transfected with plasmids encoding EGFP-tagged AcP10 or AcP10(SA-). After treatment with the indicated arsenite concentrations for $1 \mathrm{~h}$, elF2B was purified from cell lysates and associations of AcP10, elF2 and p-elF2 were analysed using antibodies directed against EGFP, elF2 $\alpha$ and p-elF2 $\alpha$, respectively. c, Flow cytometry histograms indicating the transfection efficiencies in the experiment shown in $\mathbf{b}$

in sequence, structure and function, although often involved in counteracting antiviral responses ${ }^{31}$. We found that the $\mathrm{L}$ protein of the human gastroenteric pathogen $\mathrm{AiV}$, like AcP10, prevents both PKR- and HRI-dependent stress granule formation, but not stress granule formation induced by pateamine A (Fig. 6a). Furthermore, flow cytometry analysis showed that AiVL rescues translation even at high levels of p-eIF2 (Fig. 6b). To identify residues important for AiVL's ISR antagonist function, we used an alanine scanning approach and determined two cysteines in AiVL (C53 and C56) to be essential for inhibition of stress granule formation (Extended Data Fig. 6a), for the rescue of translation in the presence of p-eIF2 $\alpha$ (Extended Data Fig. 6b) and for binding eIF2B (Extended Data Fig. 6c). Importantly, as shown in Extended Data Fig. 6c, AiVL ${ }^{\mathrm{C} 6 \mathrm{~A}}$ fails to bind eIF2B even when expressed at higher levels than wild-type AiVL. Subunits of eIF2B co-purified from cell lysates with AiVL as bait but not with mutant $\mathrm{L}^{\mathrm{C} 56 \mathrm{~A}}$, and eIF2B-AiVL complexes were stable under high-salt conditions that disrupt eIF2-eIF2B interaction, strongly suggesting that AiVL binds eIF2B directly (Fig. 6c). Accordingly, AiVL co-purified with eIF2B in reciprocal pull-down assays (Fig. 6d). Importantly, eIF2B complexes purified from cells expressing AiVL, relative to those purified from cells expressing AiVL ${ }^{\mathrm{C} 65 \mathrm{~A}}$, contained strongly reduced amounts of p-eIF2, suggesting that AiVL, like AcP10, prevents p-eIF2-eIF2B association (Fig. 6e,f).

To test the function of AiVL in the context of the natural infection, we generated a recombinant $\mathrm{AiV}$ in which the $\mathrm{L}$ protein was inactivated by a double C53A/C56A mutation through reverse genetics. Cells infected with wild-type $\mathrm{AiV}$ or $\mathrm{AiV}-\mathrm{L}^{\mathrm{C} 53 \mathrm{~A} / \mathrm{C} 56 \mathrm{~A}}$ contained similar quantities of dsRNA and equally high levels of p-eIF2 (Fig. 7a,b). In those infected with AiV-L $\mathrm{L}^{\mathrm{C} 53 \mathrm{~A} / \mathrm{C} 56 \mathrm{~A}}$, global translation was severely repressed (Fig. 7a) and stress granules were formed (Fig. 7b,c). In contrast, in cells infected with wild-type $\mathrm{AiVL}$, stress granules were not observed at any time during infection and global translation rates remained intact (Fig. $7 \mathrm{a}-\mathrm{c}$ and Extended Data Fig. 7). To assess the impact of loss of AIVL function on virus propagation, we performed single-step growth curve analyses of wild-type $\mathrm{AiV}$ and $\mathrm{AiV}-\mathrm{L}^{\mathrm{C} 53 \mathrm{~A} / \mathrm{C} 56 \mathrm{~A}}$. Inactivation of $\mathrm{AiVL}$ consistently resulted in delayed propagation and tenfold lower titres in Vero E6 cells (Fig. 7d). To determine whether this replication defect of AiV-L $\mathrm{L}^{\mathrm{C} 33 \mathrm{~A} / \mathrm{C} 56 \mathrm{~A}}$ is caused by its inability to counteract the ISR, we transfected HeLa wild-type and HeLa PKR ${ }^{\mathrm{KO}}$ cells 


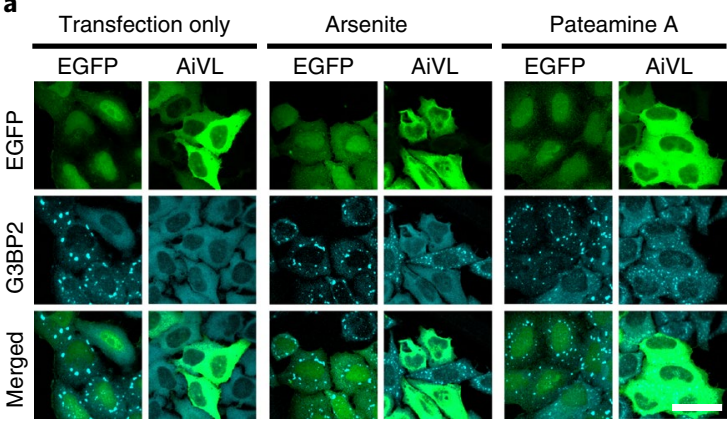

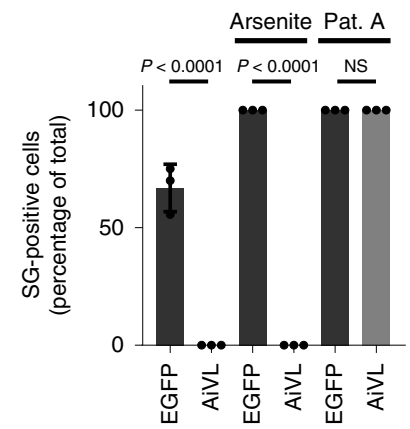

b EGFP AiVL-EGFP
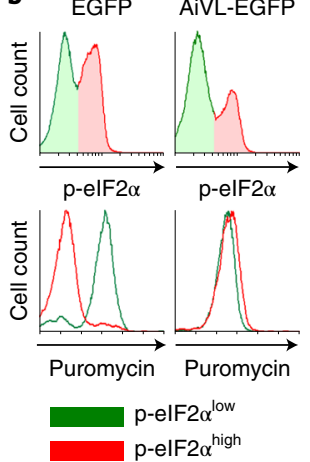

IP: AiVL/AcP10

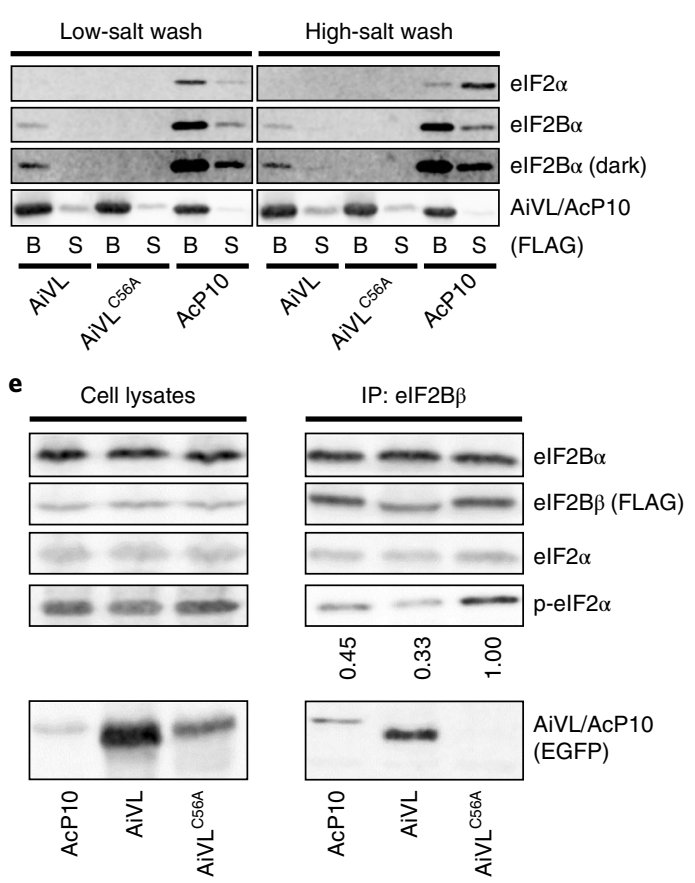

IP: elF2B $\beta$
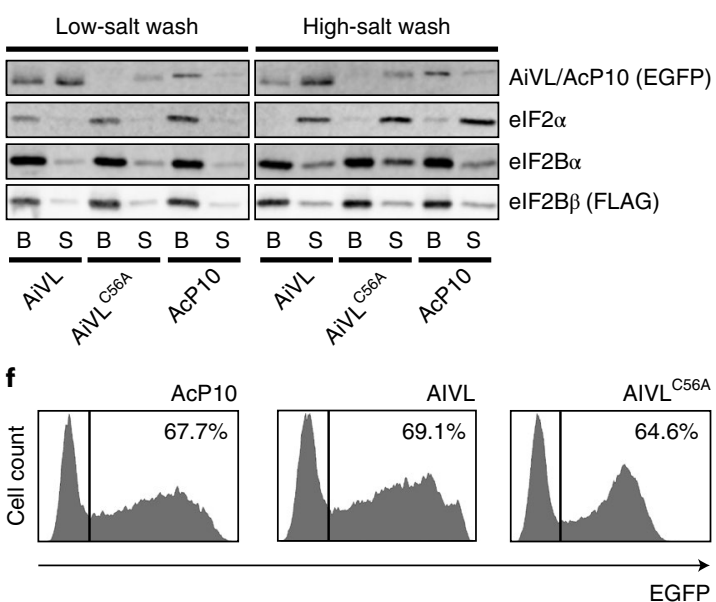

Fig. 6 | The picornavirus protein AiVL blocks ISR signalling using a similar mechanism of action to that of AcP10. a, IFA analysis of stress granule formation in HeLa cells transiently overexpressing the indicated EGFP fusion proteins, either without additional treatment (left), after treatment with $500 \mu \mathrm{M}$ arsenite for $45 \mathrm{~min}$ (middle) or after treatment with $100 \mathrm{nM}$ pateamine A for $2 \mathrm{~h}$ (right). Scale bar, $50 \mu \mathrm{m}$. Quantifications (means $\pm \mathrm{s} . \mathrm{d}$.) of the percentages of stress granule-positive cells ( $n=3$ biologically independent experiments) are given in the bar graph to the right. Statistical analysis was assessed using one-way ANOVA with a Bonferroni post-hoc test. b, Flow cytometry analysis of p-elF2 levels (top) and active translation (bottom) in cells transiently transfected with plasmids encoding the indicated proteins. Only transfected cells (EGFPos) are shown. Cells stressed by the plasmid DNA transfection ( $p$-elF2 $\alpha^{\text {high }}$ ) are shown in red and non-stressed cells ( $p$-elF2 $\alpha^{\text {low }}$ ) are shown in green. c, The indicated FLAG-tagged proteins were transiently expressed and isolated from cell lysates. In each sample, co-purification of elF2 and elF2B was assessed by western blotting for their respective $\alpha$ subunits. B indicates bead-bound proteins and $\mathrm{S}$ indicates proteins present in the supernatant fraction. $\mathbf{d}$, The indicated EGFP-tagged proteins were transiently expressed in HeLa-eIF2B $\beta$-3XFLAG cells. Subsequently, FLAG-tagged elF2B was isolated from cell lysates. In each sample, co-purification of viral proteins was assessed by western blotting for EGFP. e, The indicated EGFP-tagged proteins were transiently expressed in HeLa-elF2B $\beta$-3xFLAG cells. Cells were stressed using $500 \mu \mathrm{M}$ arsenite for $1 \mathrm{~h}$ and elF2B was isolated from cell lysates. Co-purified elF2, p-elF2 and viral proteins were assessed using the indicated antibodies. Levels of p-eIF2, corrected for the amounts found in the cell lysates and relative to the control sample AiVL ${ }^{\mathrm{C} 6 \mathrm{~A}}$, are indicated.

f, Transfection efficiencies obtained in the experiment shown in $\mathbf{e}$.

with in vitro-transcribed viral RNA and assessed the production of infectious virus over time. We resorted to RNA transfections because HeLa cells are not susceptible to AiV. In Hela wild-type cells, AiV-L $\mathrm{L}^{\mathrm{C} 33 \mathrm{~A} / \mathrm{C} 56 \mathrm{~A}}$ displayed a substantial loss of fitness and replicated to titres roughly 15 - to 20 -fold lower than those of wild-type $\mathrm{AiV}$ (Fig. 7e,g). However, in HeLa PKR ${ }^{\mathrm{KO}}$ cells, AiV-L $\mathrm{L}^{\mathrm{C} 3 \mathrm{~A} / \mathrm{C} 56 \mathrm{~A}} \mathrm{rep}-$ lication was largely rescued (on average only threefold lower titres compared with wild-type AiV; Fig. 7f,g). The findings indicate that the reduced propagation of AiV-L ${ }^{\mathrm{C} 53 \mathrm{~A} / \mathrm{C} 56 \mathrm{~A}}$ in wild-type HeLa cells is predominantly caused by PKR-induced ISR activation and that inhibition of the ISR by AiVL is necessary for optimum virus replication. Taken together, our data show that AiVL counteracts the ISR in a manner similar to that of AcP10, not only under conditions of heterologous expression, but also in AiV-infected cells, and that this function is necessary for efficient $\mathrm{AiV}$ propagation under natural conditions.

\section{Discussion}

ISR-mediated inhibition of (viral) protein synthesis presents a potent antiviral defence mechanism. Consequently, numerous 


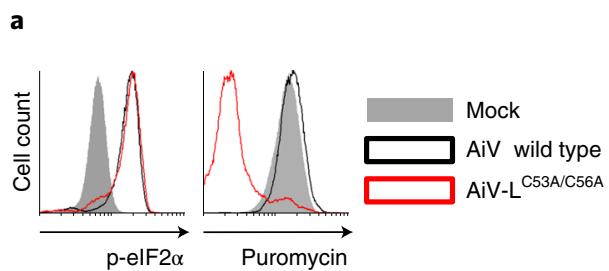

b
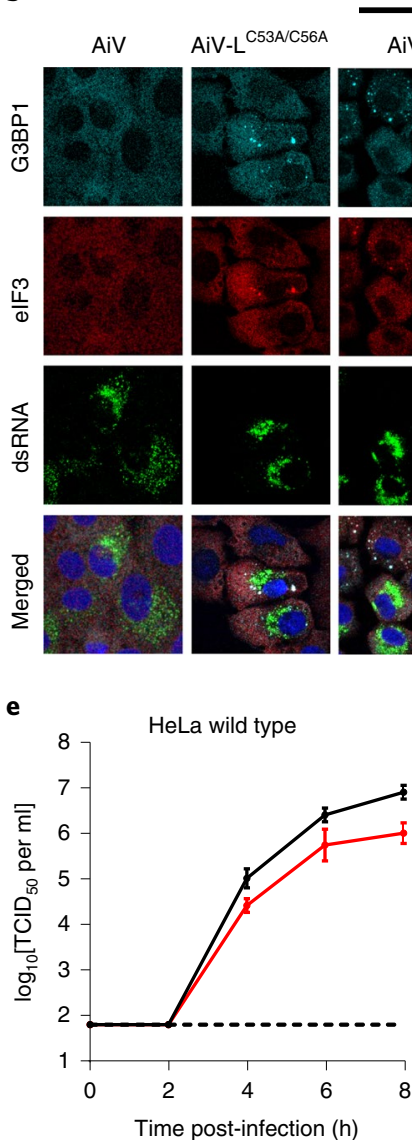
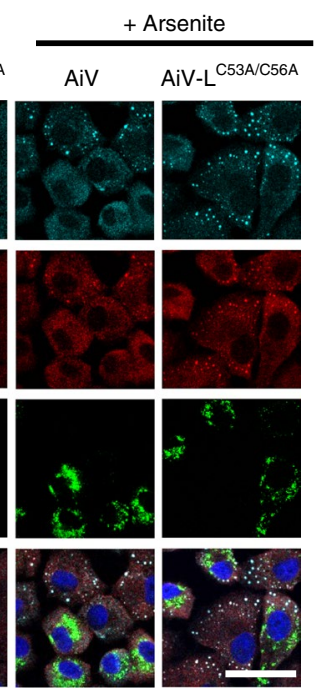

c

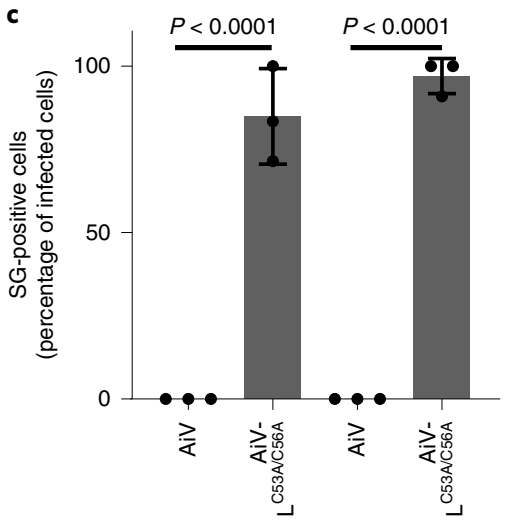

d

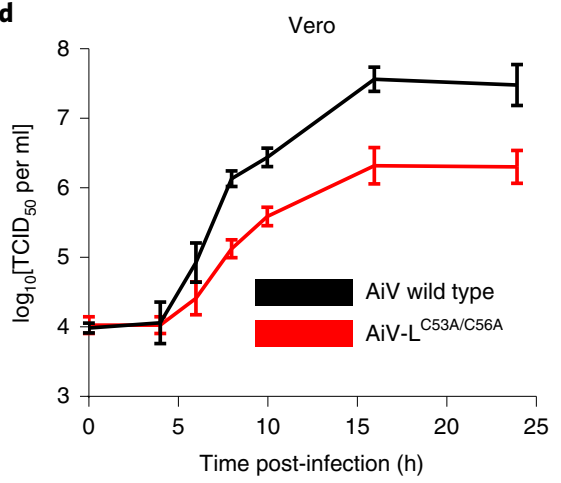

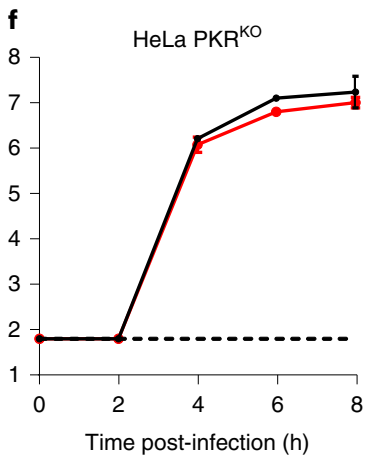

g

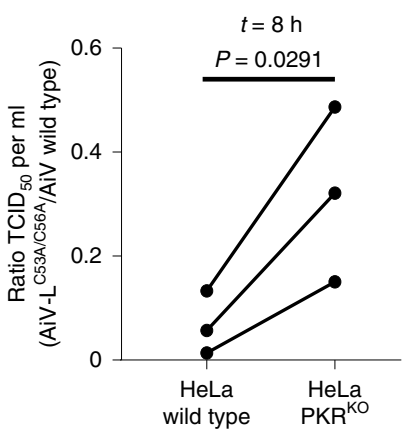

Fig. 7 I ISR antagonism by AiVL enhances virus propagation. a, Vero cells were infected (MOI=5) with the recombinant AiV wild type or AiV-L ${ }^{\mathrm{C} 53 \mathrm{~A} / \mathrm{C} 56 \mathrm{~A}}$. At $8 \mathrm{~h}$ post-infection, cells were fixed and analysed by flow cytometry for $\mathrm{p}$-elF $2 \alpha$ content and active translation rates. $\mathbf{b}$, Vero cells were infected (MOI $=1$ ) for $8 \mathrm{~h}$ with the recombinant AiV wild type or AiV-L ${ }^{\mathrm{C} 53 \mathrm{~A} / \mathrm{C5} 6 \mathrm{~A}}$. During the final hour of the experiment, cells received no additional treatment (left) or were treated with $500 \mu \mathrm{M}$ arsenite (right). dsRNA content and stress granule formation were analysed by IFA using the indicated antibodies. Scale bar, $50 \mu \mathrm{m}$. c, Quantification of the percentages of stress granule-positive infected cells (means \pm s.d.) from $n=3$ biologically independent experiments, as shown in $\mathbf{b}$. Statistical significance was determined using one-way ANOVA with a Bonferroni post-hoc test. d, Representative single-step replication curve analysis ( $n=3$ technical replicates) of the AiV wild type and AiV-L ${ }^{\text {C53A/C56A }}$ in Vero cells. The experiment was performed twice independently with similar results. Shown are means \pm s.d. TCID $_{50}, 50 \%$ tissue culture infective dose. e,f, HeLa wild-type cells (e) or HeLa PKR ${ }^{K O}$ cells (f) were transfected with in vitro-transcribed AiV wild-type RNA (black lines) or AiV-L ${ }^{C 53 A / C 56 A}$ RNA (red lines). The production of infectious virus was measured by end-point dilution assays at the indicated time points post-infection. Shown are the results from an example experiment, with means \pm s.d. of triplicate technical measurements. The experiments were performed three times independently with similar results. The dashed horizontal lines indicate the detection limit of the assays. $\mathbf{g}$, Graph showing the average values obtained in $n=3$ biologically independent replicates, each performed with technical triplicates, of the assay shown in $\mathbf{e}$ and $\mathbf{f}$ at the $8 \mathrm{~h}$ time point. The values shown are the ratios of the titres obtained for AiV-L $\mathrm{L}^{\mathrm{C} 53 \mathrm{~A} / \mathrm{C5} 6 \mathrm{~A}}$ over those obtained for the AiV wild type. Statistical significance was determined using a two-tailed paired-sample $t$-test.

viruses have evolved strategies to either prevent activation of ISR sensor proteins or to reverse eIF2 phosphorylation. Here, we report the identification of viral ISR antagonists that do not impact the level of p-eIF2, but instead target the ISR at its core: the interplay between p-eIF2 and eIF2B. The coronavirus protein AcP10 and the picornavirus protein AiVL engage in stable interactions with eIF2B and act as competitive inhibitors of p-eIF2 binding, without affecting the association of eIF2B's substrate eIF2. Consequently, eIF2B GEF activity cannot be inhibited by p-eIF2, ensuring ongoing translation even under stress conditions in which the majority of the cellular eIF2 pool is phosphorylated. Bw-CoV AcP10 and AiVL share no significant sequence identity, there are no indications for structural similarity, and while the origin of AcP10 as uridine kinase is evident, that of AiVL is unknown. Our findings thus suggest 
that representatives of two distinct orders of positive-strand RNA viruses adopted a similar strategy of suppressing the ISR through convergent evolution. In line with the classification of viral ISR inhibition as presented in the introduction, we refer to these proteins as class 4 ISR antagonists.

AcP10 and AiVL mode of action and implications. The results from reciprocal affinity purification assays and (cross-linking) mass spectrometry provide unambiguous evidence that AcP10 and AiVL associate with eIF2B. It remains to be determined whether they prevent p-eIF2 from binding by directly blocking the p-eIF2 binding site, or indirectly by inducing an eIF2B conformation incompatible with the p-eIF2-eIF2B interaction. Interestingly, recent cryogenic electron microscopy structures for mammalian eIF2-eIF2B and p-eIF2-eIF2B complexes ${ }^{32,33}$ combined with the results from our cross-linking/mass spectrometry analysis of AcP10-eIF2B suggest that AcP10 roughly localizes to an area of eIF2B close to the eIF2B $\alpha /$ IF $2 B \delta$ interface that is occupied by p-eIF $2 \alpha$ but not eIF2 $\alpha$. Whether AcP10 binds eIF2B as a monomer or homomultimer, and whether AcP10 does so in its UCK fold or in an alternative conformation, remain open questions. Elucidation of the details of the molecular mechanism by which AcP10 and AiVL inhibit the ISR awaits structural analysis of their complexes with eIF2B. This notwithstanding, our findings challenge the view in the field that eIF2 and p-eIF2 bind to eIF2B in essentially identical fashion ${ }^{34,35}$; if this were the case, we would expect any antagonist disrupting p-eIF2 eIF2B and p-eIF2-eIF2B, blocking formation of the latter complex exclusively, eIF2 and p-eIF2 must differ in their binding characteristics. These findings not only further our molecular insight into the eIF2-eIF2B interaction but may also be of future clinical relevance. Chronic activation of the ISR has been implicated in a variety of conditions, including developmental defects, prion disease, traumatic brain injury and cancer ${ }^{20,36-38}$. Adverse effects of the ISR can be alleviated by pharmacological modulation, as demonstrated with a small molecule inhibitor, ISRIB, that boosts eIF2B's basal GEF activity by promoting eIF2B dimerization ${ }^{19,20,39,38,40-42,]}$. Our observations suggest that the p-eIF2-eIF2B association may present another druggable vulnerability of the ISR. Future comparative structural analyses of eIF2B macrocomplexes containing AcP10 or AiVL, eIF2 and/or p-eIF2 may reveal target binding sites on eIF2B amenable to structure-based drug design and thereby facilitate the development of new, and possibly more potent, ISR inhibitors of therapeutic relevance.

AcP10 origin and evolution from UCK to ISR antagonist. Coronaviruses are exceptional among RNA viruses with respect to genetic complexity and genome plasticity, probably owing to their propensity for frequent heterologous RNA recombination. During coronavirus radiation and diversification, a basic set of genes for the replication machinery and structural proteins was complemented by a specific set of accessory genes, which are unique to specific virus (sub)groups and reflect their different evolutionary trajectories. These accessory genes, encoding proteins that increase viral fitness in a variety of ways, often are of unknown origin without cellular or viral counterpart, and in many cases may well have evolved de novo. AcP10 is one of the few coronavirus accessory proteins for which an origin may be inferred. AcP10 shares $\sim 30 \%$ sequence identity with cellular UCKs-an ancient protein family widely distributed in Bacteria and Eukarya ${ }^{43}$-and hence its gene is clearly of cellular origin, either acquired directly from a host or through an unknown viral intermediate. The donor of the gene is not immediately evident as AcP10 is distinct from all cellular UCKs described so far, as well as from those found in giant viruses, and the phylogenetic signal has been blurred, probably due to extensive genetic drift. Importantly, however, AcP10's function as an UCK is conserved, indicating that the UCK function has been advantageous to the virus over the course of evolution. The acquisition of this gene probably provided the virus with an opportunity to explore sequence space, since any adaptation that does not interfere with its primary UCK function is allowed. This may ultimately have yielded a second, UCK-independent function for AcP10 as an extraordinarily potent antagonist of the ISR.

\section{Methods}

Cell lines. HeLa R19, BHK-21, Vero E6 and HEK293T cells were cultured in Dulbecco's modified Eagle's medium supplemented with $10 \%$ (vol/vol) foetal calf serum at $37^{\circ} \mathrm{C}$. BHK-21 cells, HEK293T cells and Vero E6 cells, obtained from the American Type Culture Collection (ATCC) (that is, ATCC CCL-10, ATCC CRL-3216 and ATCC CRL-1586, respectively) were validated by ATCC through short tandem-repeat profiling. HeLa R19 cells were obtained from G. Belov (University of Maryland and Virginia-Maryland Regional College of Veterinary Medicine $)^{44,45}$. HeLa R19-eIF2B $\beta$-3 $\times$ FLAG cells were kindly provided by the laboratory of $\mathrm{D}$. Ron, having previously been created by inserting a triple FLAG sequence at the $\mathrm{N}$ terminus of the eIF2B $\beta$ gene by CRISPR-Cas 9 gene editing ${ }^{30}$. HeLa R19 $\mathrm{PKR}^{\mathrm{KO}}$ were created by inactivating the PKR gene using CRISPR-Cas9. Knockout was confirmed using western blotting and PCR amplification of the genomic region of interest ${ }^{9}$. All cell lines were tested and found negative for Mycoplasma contamination.

Plasmids. Recombinant proteins for uridine kinase assays were expressed in HEK293T cells using pCAGGS plasmids (Addgene; plasmid 41583) in which the original coding sequence was replaced with ORFs that encode the indicated Strep-tagged proteins under the control of a chicken $\beta$-actin promoter. For mammalian overexpression of EGFP fusion proteins in Immunofluorescence assay (IFA) and flow cytometry experiments, we used pEGFP-N constructs (ClonTech; plasmid U55762.1)

The ATF4 reporter construct (pcDNA3-ATF4-RE-EGFP-Strep2) was created in the context of a pcDNA3.1 vector (Addgene; plasmid V790-20) and induces expression of an mRNA that contains the ATF4 upstream ORFs, as well as an ORF encoding a Strep-tagged EGFP protein. The mRNA encoded by the ATF4 reporter construct and the mRNA encoded by the negative control (pcDNA3-EGFP-Strep2) reporter construct are schematically shown in Fig. 3a.

For overexpression of TAP-tagged proteins in co-immunoprecipitation experiments, we used pcDNA3.1 constructs encoding the indicated proteins with an $\mathrm{N}$-terminal multi-component TAP tag (S-tag, 3C protease cleavage site, Strep2-tag and FLAG-tag). The EMCV infectious clone pM16.1 (ref. ${ }^{17}$ ) and AiV infectious clone $\mathrm{pAV}^{46}$ were described previously. A full list of the plasmids used in this study is given in Supplementary Table 2.

Viruses. EMCV-L ${ }^{\mathrm{zn}}$ was described previously ${ }^{17}$. The gene encoding AcP10 or AcP10(SA-) with a carboxy-terminal VFETQ|G cleavage site was inserted at the $5^{\prime}$ end of the viral polyprotein coding sequence in the pM16.1 infectious clone (resulting in pM16.1-AcP10-L ${ }^{2 \mathrm{n}}$-VFETQG and pM16.1-AcP10 ${ }^{\mathrm{H} 193 \mathrm{~A} /}$

${ }^{\mathrm{H} 200 \mathrm{~A}}-\mathrm{L}^{\mathrm{zn}}-\mathrm{VFETQG}$, respectively) ${ }^{17}$. AiV was obtained from the pAV infectious clone $^{46}$, and mutant AiV was obtained from pAV in which double the mutation $\mathrm{C} 53 \mathrm{~A} / \mathrm{C} 56 \mathrm{~A}$ in $\mathrm{L}$ was introduced by site-directed mutagenesis ( $\mathrm{pAV}-\mathrm{L}^{\mathrm{C} 53 \mathrm{~A} / \mathrm{C} 56 \mathrm{~A}}$ ). To create infectious virus, pM16.1 and pAV plasmids were linearized by BamHI or HindIII restriction, respectively, and infectious RNA was synthesized by in vitro transcription from a T7 promoter using the RiboMAX in vitro transcription system (Promega). The RNA was purified using the NucleoSpin RNA mini kit (Macherey-Nagel) according to the manufacturer's protocol, and a total of $1 \mu \mathrm{g}$ RNA was subsequently transfected in a subconfluent T225 flask of BHK-21 cells (EMCV) or Vero cells (AiV) using Lipofectamine 2000 (Invitrogen) transfection reagent according to the manufacturer's protocol. After $2-4 \mathrm{~d}$, when complete cytopathic effect was observed, virus stocks were freeze-thawed three times and cell debris spun down. Virus in the supernatants was purified and concentrated by ultracentrifugation $(100,000 \mathrm{~g})$ for $16 \mathrm{~h}$ on a $30 \%$ sucrose cushion, and virus pellets were resuspended in phosphate-buffered saline (PBS). The integrity of the ORF10 gene in EMCV-L $\mathrm{L}^{\mathrm{zn}}-\mathrm{AcP} 10$ and EMCV- $\mathrm{L}^{\mathrm{zn}}-\mathrm{AcP} 10(\mathrm{SA}-)$, and the AiVL gene in AiV and $\mathrm{AiV}^{\mathrm{C} 53 / 56 \mathrm{~A}}$, was confirmed by isolation of the viral RNA using the NucleoSpin RNA virus mini kit (Macherey-Nagel) according to the manufacturer's protocol. Subsequently, complementary DNA was synthesized using the SuperScript III first-strand synthesis system (Invitrogen) according to the manufacturer's protocol, and the region of interest was PCR amplified and Sanger sequenced.

Uridine kinase assay. Purified protein samples were prepared by transient transfection of pCAGGS-Strep constructs encoding the relevant proteins in HEK293T cells. After overnight expression, cells were lysed in lysis buffer (40 mM Tris- $\mathrm{HCl}$ (pH 7.4), $50 \mathrm{mM} \mathrm{NaCl}, 10 \mathrm{mM}$ EDTA, 1\% NP-40 and cOmplete Mini Protease Inhibitor Cocktail (Roche)) and cell debris were removed by centrifugation. Subsequently, soluble Strep-tagged proteins were bound to Strep-Tactin beads (IBA) for $2 \mathrm{~h}$ at $4^{\circ} \mathrm{C}$. Samples were washed three times in wash buffer (40 mM Tris- $\mathrm{HCl}$ (pH 7.4), $50 \mathrm{mM} \mathrm{NaCl}$ and $1 \mathrm{mM}$ EDTA) and the protein was eluted in wash buffer containing $10 \mathrm{mM}$ desthiobiotin. Protein concentrations 
were measured on a NanoDrop 1000 spectrophotometer (Thermo Fisher Scientific). Reaction mixtures were set up using $100 \mathrm{ng}$ of the indicated purified Strep-tagged protein, $2 \mu \mathrm{g}$ uridine, $4 \mu \mathrm{g}$ ATP, $1 \mathrm{mM}$ dithiothreitol (DTT) and $0.1 \mu \mathrm{g}$ bovine serum albumin (BSA) in $1 \times$ NEBuffer 2 (New England Biolabs) in a total volume of $10 \mu \mathrm{l}$. After $1 \mathrm{~h}$ incubation at $37^{\circ} \mathrm{C}$, a total of $1.5 \mu \mathrm{l}$ was applied stepwise $(6 \times 0.25 \mu \mathrm{l})$ on a PEI Cellulose F plate (Merck Millipore). The plate was dried after each application. The base of the plate was then put in the mobile phase solution (distilled water $+500 \mathrm{mM} \mathrm{NaCl}+1 \mathrm{mM} \mathrm{LiCl}$ ) until the liquid front almost reached the top of the plate. The presence of U, UMP, ATP and ADP was visualized under a short-wavelength $(254 \mathrm{~nm})$ ultraviolet lamp.

IFA. HeLa cells were seeded on glass cover slips in a 24-well cluster at subconfluent densities. The cells were transfected overnight with $500 \mathrm{ng}$ of the indicated plasmids using FuGENE 6 reagent (Roche) according to the manufacturer's protocol. The next day, cells were left untreated, treated with $500 \mu \mathrm{M}$ arsenite (Riedel-de Haën) or treated with $100 \mathrm{nM}$ pateamine A for $30 \mathrm{~min}$ and subsequently fixed in PBS $+4 \%$ paraformaldehyde (PFA). Alternatively, cells were infected with the indicated recombinant EMCV (multiplicity of infection $(\mathrm{MOI})=2$ ) for $5 \mathrm{~h}$ or $\mathrm{AiV}(\mathrm{MOI}=1)$ for $8 \mathrm{~h}$ and fixed in PBS $+4 \%$ PFA. Samples were permeabilized by incubation in PBS $+0.1 \%$ Triton X-100 for 5 min and blocked in block buffer $\left(\mathrm{PBS}+2 \% \mathrm{BSA}+50 \mathrm{mM} \mathrm{NH}_{4} \mathrm{Cl}\right)$ for $1 \mathrm{~h}$. The cells were incubated in block buffer containing mouse anti-hG3BP1 (1:200; BD Biosciences), rabbit anti-hG3BP1 (1:200; Aviva), goat anti-eIF3ๆ (1:200; SantaCruz), rabbit anti-G3BP2 (1:200; Bethyl) and/or mouse anti-dsRNA (1:1,000; English \& Scientific Consulting) for $45 \mathrm{~min}$. After three wash steps in block buffer, cells were incubated with secondary antibody donkey anti-Mouse cy5 (The Jackson Laboratory), donkey anti-Rabbit Alexa 647 (Life Technologies), donkey anti-Goat Alexa 568 (Life Technologies) and/or donkey anti-Mouse Alexa 488 (Life Technologies) at a concentration of 1:200 in block buffer. Cells were washed once in block buffer and once in distilled water. Cover glasses were then mounted on slides in FluorSave Reagent (Calbiochem) and visualized by confocal microscopy using a Leica SPE-II (Leica Microsystems).

Flow cytometry assay. HeLa cells were seeded on glass cover slips in a 24-well cluster at subconfluent densities. The next day, cell layers were transfected with $500 \mathrm{ng}$ of the indicated plasmids using FuGENE 6 reagent (Roche) according to the manufacturer's protocol. After overnight incubation, cells were treated with $500 \mu \mathrm{M}$ arsenite or left untreated. Alternatively, cells were infected with the indicated recombinant EMCV $(\mathrm{MOI}=5)$ for $5 \mathrm{~h}$, or recombinant $\mathrm{AiV}(\mathrm{MOI}=5)$ for $8 \mathrm{~h}$. Puromycin labelling of active translation was done by exposing cells to $20 \mu \mathrm{g} \mathrm{ml}^{-1}$ puromycin during the final $15 \mathrm{~min}$ of the assay. Cells were then released by trypsin treatment and fixed in 4\% PFA in PBS for $30 \mathrm{~min}$, and subsequently permeabilized in ice-cold $\mathrm{MeOH}$ for $10 \mathrm{~min}$. The samples were washed twice in FACS buffer $(\mathrm{PBS}+1 \% \mathrm{BSA})$ and subsequently incubated with the primary antibodies mouse anti-Puromycin (Merck Millipore) and rabbit anti-p-eIF2 $\alpha$ (Abcam) at 1:100 dilution in FACS buffer for $45 \mathrm{~min}$. Samples were washed twice in FACS buffer and subsequently incubated in the secondary antibodies donkey anti-Mouse Cy5 (The Jackson Laboratory) and goat anti-Rabbit Alexa 594 (Invitrogen) at 1:200 dilution in FACS buffer for $45 \mathrm{~min}$. Samples were washed once in FACS buffer and kept in FACS buffer $+2 \%$ PFA at $4{ }^{\circ} \mathrm{C}$ until analysis with a FACSCanto II (BD Biosciences). The gating strategy used in the flow cytometry analyses is briefly explained in Extended Data Fig. 8.

Western blot analysis. Cells were lysed in ice-cold lysis buffer $(40 \mathrm{mM}$ Tris- $\mathrm{HCl}$ (pH 7.4), $150 \mathrm{mM} \mathrm{NaCl}, 10 \mathrm{mM}$ EDTA, $1 \%$ NP-40, phosphatase inhibitor cocktail 2 (Sigma-Aldrich), phosphatase inhibitor cocktail 3 (Sigma-Aldrich) and cOmplete Mini Protease Inhibitor Cocktail (Roche)) for $30 \mathrm{~min}$. Cell debris were pelleted and the protein concentration in the supernatant was determined using the Pierce BCA assay (Thermo Fisher Scientific) according to the manufacturer's protocol. For each sample, $35 \mu \mathrm{g}$ protein in $1 \times$ Laemmli sample buffer (LSB) was separated on $12.5 \%$ sodium dodecyl sulfate polyacrylamide gel electrophoresis (SDS-PAGE) gels and transferred to nitrocellulose membranes by wet transfer. Membranes were probed with the indicated primary antibodies, mouse anti-Puromycin (Merck Millipore), rabbit anti-p-eIF2 $\alpha$ (Abcam), rabbit anti-eIF2 $\alpha$ (Cell Signaling), rabbit anti-EGFP ${ }^{47}$, mouse anti-Tubulin (Sigma-Aldrich), mouse anti-FLAG (Sigma-Aldrich), rabbit anti-eIF2B $\varepsilon$ (Abcam) or rabbit anti-eIF2B $\alpha$ (Proteintech), all used at 1:1,000 dilution. After three wash steps, membranes were incubated in secondary antibodies goat anti-Mouse IRDye 680 (LI-COR; 1:15,000) or goat anti-Rabbit IRDye 800 (LI-COR; 1:15,000). Fluorescence images were captured using the Odyssey imager (LI-COR). Unless otherwise indicated, all western blots shown within the same figure panels were performed in parallel and analysed using the same settings.

${ }^{35} \mathrm{~S}$ radiolabelling assay. HeLa $\mathrm{PKR}^{\mathrm{KO}}$ cells were seeded in six-well clusters to subconfluent densities. The next day, cells were co-transfected with $1.5 \mu \mathrm{g}$ pEGFP-N1 plasmid encoding AcP10-EGFP or AcP10(SA-)-EGFP together with $0.5 \mu \mathrm{g}$ of the indicated pcDNA3 reporter construct using FuGENE 6 transfection reagent. After overnight incubation, the medium was replaced with medium without methionine and cysteine for $30 \mathrm{~min}$. Subsequently, arsenite was added to the medium at the indicated final concentrations for another $30 \mathrm{~min}$. Then, ${ }^{35} \mathrm{~S}$ Met/Cys (Perkin Elmer) was added to the medium at a final concentration of $10 \mu \mathrm{Ci} \mathrm{ml}^{-1}$ for $90 \mathrm{~min}$. The supernatant was removed, and cells were washed three times in PBS and then lysed in lysis buffer $(20 \mathrm{mM}$ Tris- $\mathrm{HCl}$ (pH 7.4), $100 \mathrm{mM} \mathrm{NaCl}, 1 \mathrm{mM}$ EDTA, $1 \%$ Triton X-100 and cOmplete Mini Protease Inhibitor Cocktail (Roche)). Cell debris were spun down, and supernatants were transferred to new tubes. A total of $10 \mu \mathrm{l}$ of Strep-Tactin beads (IBA) were added to each sample and incubated rotating overnight at $4{ }^{\circ} \mathrm{C}$. The next day, beads were washed three times in RIPA buffer (10 mM Tris- $\mathrm{HCl}$ (pH 7.4), $150 \mathrm{mM} \mathrm{NaCl}, 0.1 \%$ sodium dodecyl sulfate, $1 \%$ sodium deoxycholate and $1 \%$ NP-40) and resuspended in $1 \times$ LSB. Subsequently, samples were separated by SDS-PAGE, and gels were vacuum-dried on Whatman paper at $80^{\circ} \mathrm{C}$. Gels were subsequently analysed on a phosphorimager (FUJI). Background subtraction and signal intensity analysis were done using ImageJ software.

Immunoprecipitation of TAP-tagged AcP10. HEK293T cells were transiently transfected with pcDNA3 plasmids encoding the indicated TAP-tagged (S-tag, 3C protease cleavage site, StrepII-tag and FLAG-tag, fused to the protein N terminus) proteins under the control of a cytomegalovirus promoter using polyethylenimine (PEI) transfection. Briefly, for each $14.5 \mathrm{~cm}$ dish, $15 \mu \mathrm{g}$ DNA was mixed with $1.5 \mathrm{ml}$ Opti-MEM. Subsequently, $100 \mu \mathrm{l}$ of a $1 \mathrm{mg} \mathrm{ml}^{-1}$ PEI solution was added, mixed thoroughly and incubated for $30 \mathrm{~min}$ at room temperature before adding to the cells. For each sample, $2 \times 10^{7}$ cells were lysed in lysis buffer $(40 \mathrm{mM}$ Tris- $\mathrm{HCl}$ (pH 7.4), $50 \mathrm{mM} \mathrm{NaCl}, 10 \mathrm{mM}$ EDTA, $1 \%$ NP-40, cOmplete Mini Protease Inhibitor Cocktail (Roche), phosphatase inhibitor cocktail 2 (Sigma-Aldrich) and phosphatase inhibitor cocktail 3 (Sigma-Aldrich)) for 15 min on ice. After spinning down cell debris, supernatants were incubated with $20 \mu \mathrm{l} \mathrm{S-protein}$ beads (Novagen) for $2 \mathrm{~h}$ at $4{ }^{\circ} \mathrm{C}$. S-protein beads were washed three times in wash buffer (40 mM Tris- $\mathrm{HCl}$ (pH 7.4), $50 \mathrm{mM} \mathrm{NaCl}$ and $1 \mathrm{mM}$ EDTA) and once in $3 \mathrm{C}^{\text {pro }}$ cleavage buffer (Thermo Fisher Scientific) and subsequently resuspended in $200 \mu \mathrm{l} 3 \mathrm{C}$ cleavage buffer. Protein was released from beads by adding $3 \mathrm{C}^{\text {pro }}$ overnight at $4{ }^{\circ} \mathrm{C}$, according to the HRV 3C Protease Solution Kit manufacturer's protocol (Thermo Fisher Scientific). The next day, the beads were spun down and the supernatant was transferred to a new tube. In total, $10 \mu \mathrm{l}$ of Strep-Tactin beads (IBA) were added to each sample and incubated for $1 \mathrm{~h}$ at $4^{\circ} \mathrm{C}$. Beads were washed three times in wash buffer and then resuspended in $1 \times$ LSB. Samples were run on SDS-PAGE gels and used for western blotting or mass spectrometry analysis.

Immunoprecipitation of FLAG-tagged eIF2B $\beta$. HeLa cells stably expressing FLAG-tagged eIF2B $\beta^{30}$ were seeded at $2.5 \times 10^{6}$ cells per dish (surface area $=180 \mathrm{~cm}^{2}$ ), with four dishes per sample. The next day, cells were transfected with $15 \mu \mathrm{g}$ of the indicated plasmids using Lipofectamine 2000 (Invitrogen) reagent according to the manufacturer's instructions. After $2 \mathrm{~d}, \sim 4 \times 10^{7}$ cells per sample were harvested and lysed in $500 \mu \mathrm{l}$ lysis buffer ( $50 \mathrm{mM}$ Tris- $\mathrm{HCl}$ (pH 7.4), $150 \mathrm{mM}$ $\mathrm{NaCl}, 1 \mathrm{mM}$ EDTA, 1 mM DTT, 10\% glycerol, 1\% Triton X-100, cOmplete Mini Protease Inhibitor Cocktail (Roche), phosphatase inhibitor cocktail 2 (SigmaAldrich) and phosphatase inhibitor cocktail 3 (Sigma-Aldrich)). After spinning down the cell debris, supernatants were incubated for $2 \mathrm{~h}$ with $20 \mu \mathrm{l}$ anti-FLAG beads (Sigma-Aldrich), rotating at $4{ }^{\circ} \mathrm{C}$. The beads were washed four times with wash buffer (50 mM Tris- $\mathrm{HCl}$ (pH 7.4), $150 \mathrm{mM} \mathrm{NaCl}, 1 \mathrm{mM}$ EDTA, $1 \mathrm{mM}$ DTT, $10 \%$ glycerol and $1 \%$ Triton X-100), then resuspended in $1 \times$ LSB. Samples were run on SDS-PAGE gels and subsequently used for western blotting.

Affinity purification mass spectrometry. Protein samples prepared as described above were separated by SDS-PAGE and stained with Coomassie colloidal blue (Bio-Rad). Four bands were sliced out from each gel lane, which were then reduced, alkylated and digested as previously described ${ }^{48}$. Digests were subjected to nano-scale liquid chromatographic tandem mass spectrometry analysis using an Agilent 1290 Infinity ultra-high-performance liquid chromatography system (Agilent) coupled to an Orbitrap Q Exactive Plus mass spectrometer (Thermo Fisher Scientific). Dried peptides were reconstituted in $10 \%$ formic acid and delivered to a trap column (Dr. Maisch Reprosil C18; $3 \mu \mathrm{m} ; 2 \mathrm{~cm} \times 100 \mu \mathrm{m}$ ) at $5 \mu \mathrm{min}^{-1}$ with solvent $\mathrm{A}(0.1 \%$ formic acid in water). Next, peptides were chromatographically separated onto an analytical column (Agilent Poroshell EC-C18; $2.7 \mu \mathrm{m} ; 50 \mathrm{~cm} \times 75 \mu \mathrm{m}$ ) at $300 \mathrm{nl} \mathrm{min}^{-1}$, as previously described ${ }^{49}$. The gradient was as follows: $13-40 \%$ solvent $\mathrm{B}(0.1 \%$ formic acid in $80 \%$ acetonitrile $)$ over $65 \mathrm{~min}$, to $100 \%$ solvent B over $3 \mathrm{~min}$, then $1 \mathrm{~min}$ of $100 \%$ solvent B and finally equilibration of the chromatographic columns with $100 \%$ solvent $\mathrm{A}$ for the following $10 \mathrm{~min}$ before injection of the next sample. The total analysis time was $90 \mathrm{~min}$. The eluent was sprayed via distal-coated emitter tips butt-connected to the analytical column. The mass spectrometer was operated in data-dependent mode, automatically switching between mass spectrometry and tandem mass spectrometry. Full-scan mass spectrometry spectra (from $\mathrm{m} / z 375$ to 1,600 ) were acquired in the Orbitrap with a resolution of 35,000 at $\mathrm{m} / z 400$. The ten most intense ions within the survey scan were selected for high-energy collision dissociation fragmentation with the normalized collision energy set to $25 \%$. The tandem mass spectrometry automatic gain control target value was set to $5 \times 10^{4}$ with a maximum ion injection time of $120 \mathrm{~ms}$. Dynamic exclusion was set to $12 \mathrm{~s}$. Each raw data file recorded by the mass spectrometer was processed and 
quantified with Proteome Discoverer (version 2.1; Thermo Fisher Scientific) and searched against a Swiss-Prot human database (version 2016 03; 20,199 sequences) supplemented with the Bw-CoV SW1 AcP10 sequence (UniProt ID: B2BW43) using Mascot software (version 2.5.1; Matrix Science). Trypsin/P was chosen as the protease, cysteine carbamidomethylation was selected as the fixed modification, and oxidation of methionine was selected as the variable modification. Precursor and fragment mass tolerance were set to $20 \mathrm{ppm}$ and $0.05 \mathrm{Da}$, respectively. All PSMs were validated with a $1 \%$ false discovery rate using Percolator ${ }^{50}$. Only PSMs with a minimum length of six amino acids were kept. Proteins were further filtered for contaminants and highly abundant proteins (such as keratins, tubulins and ribosomal proteins), the number of unique peptides $(>0)$ and the number of peptides $(>1)$. Subsequently, the list of identified proteins was subjected to CRAPome analysis ${ }^{51}$ using default settings. To discriminate bona fide protein interactors of AcP10 from the background, we set a SAINT score threshold of 0.9 , and an FC-B score threshold (spectral count fold change between the bait and $\mathrm{L}^{\text {pro }}$ control) of 2 .

The mass spectrometry proteomics data have been deposited in the ProteomeXchange Consortium via the PRIDE partner repository ${ }^{52}$ with the dataset identifier PXD011879.

Cross-linking liquid chromatography/mass spectrometry (LC/MS) and data analysis. A total of $5 \times 10^{8}$ HEK293T cells in $4014.5 \mathrm{~cm}$ dishes were transiently transfected with pcDNA3 plasmids encoding TAP-tagged AcP10 using PEI transfection. Briefly, for each dish, $15 \mu \mathrm{g}$ DNA was mixed with $1.5 \mathrm{~m}$ Opti-MEM. Subsequently, $100 \mu \mathrm{l}$ of a $1 \mathrm{mg} \mathrm{ml}^{-1}$ PEI solution was added, mixed thoroughly and incubated for $30 \mathrm{~min}$ at room temperature before adding to the cells. The next day, the cells were lysed in lysis buffer ( $40 \mathrm{mM}$ Tris- $\mathrm{HCl}$ ( $\mathrm{pH} 7.4)$, $50 \mathrm{mM} \mathrm{NaCl}, 10 \mathrm{mM}$ EDTA, $1 \%$ NP-40 and cOmplete Mini Protease Inhibitor Cocktail (Roche)) for 15 min on ice. After spinning down the cell debris, the supernatants were incubated with $50 \mu \mathrm{l}$ Strep-Tactin beads (IBA) for $2 \mathrm{~h}$ at $4^{\circ} \mathrm{C}$ The beads were washed four times in wash buffer ( $40 \mathrm{mM}$ Tris- $\mathrm{HCl}$ ( $\mathrm{pH} 7.4)$, $50 \mathrm{mM} \mathrm{NaCl}$ and $1 \mathrm{mM}$ EDTA) and once in PBS. The isolated proteins were then cross-linked on beads using $1 \mathrm{mM}$ disuccinimidyl sulfoxide cross-linker in cross-linking buffer (20 mM HEPES ( $\mathrm{pH} 7.8)$ and $150 \mathrm{mM} \mathrm{NaCl})$ for $30 \mathrm{~min}$. The cross-linking reaction was quenched with $20 \mathrm{mM}$ Tris- $\mathrm{HCl}(\mathrm{pH} 7.8$ ) for $30 \mathrm{~min}$ at room temperature. For on-bead digestion, cross-linked proteins were denatured with $2 \mathrm{mM}$ urea, reduced with $4 \mathrm{mM} \mathrm{DTT}$ at $56^{\circ} \mathrm{C}$ for $30 \mathrm{~min}$ and alkylated with $8 \mathrm{mM}$ iodoacetamide at room temperature for $30 \mathrm{~min}$ in the dark. Proteins were digested using trypsin at an enzyme-to-protein ratio of $1: 20$ (wt/wt) at $37^{\circ} \mathrm{C}$ for $2 \mathrm{~h}$. The supernatant was removed from the beads and further digested at $37^{\circ} \mathrm{C}$ overnight. Protein digests were desalted using Sep-Pak C18 cartridges (Waters) and dried under vacuum concentrator. The digests were fractionated by strong cation exchange chromatography and five late strong cation exchange fractions were collected for further LC/MS analysis. Protein digests including cross-linked peptides were analysed using an ultra HPLC Agilent 1200 system (Agilent Technologies) coupled online to an Orbitrap Fusion mass spectrometer (Thermo Fisher Scientific). Liquid chromatography/tandem mass spectrometry analysis was performed as previously described using the CID-MS2-MS3-ETD-MS2 acquisition strategy ${ }^{29}$. Cross-link identification was performed using standalone XlinkX software ${ }^{29}$. The results were filtered by the $1 \%$ false discovery rate and all reported cross-links were manually validated.

Single-step virus replication analysis. Subconfluent layers of Vero cells were infected $(\mathrm{MOI}=2)$ with the $\mathrm{AiV}$ wild type or AiV-L ${ }^{\mathrm{C} 53 \mathrm{~A} / \mathrm{C} 56 \mathrm{~A}}$. Alternatively, $500 \mathrm{ng}$ of in vitro-synthesized viral RNA was transfected into subconfluent layers of HeLa or HeLa PKR ${ }^{\mathrm{KO}}$ cells in a 12-well cluster using Lipofectamine 2000 (Invitrogen) according to the manufacturer's instructions. After $1 \mathrm{~h}$, virus or transfection mixtures were washed away twice with PBS and new medium was added. At the indicated time points, cells were freeze-thawed three times to lyse cells and release intracellular virus. The resulting samples were titrated on Vero cells using an end-point dilution assay.

Homology modelling of AcP10 from human UCK1. Models of AcP10 were obtained via homology modelling using as a template a crystal structure of a homologue, human UCK1 (Protein Data Bank ID: 2UVQ). They share about $30 \%$ identity and $50 \%$ similarity. We performed the modelling with Modeller 9.12 (ref. ${ }^{53}$ ) and its standard loop modelling protocol ${ }^{54}$. The sequence alignment used comes from NEEDLE ${ }^{55}$ used with its default parameters. In total, 25 models were generated from which the best model after ranking by DOPE score ${ }^{56}$ was kept.

Phylogenetic analysis of uridine kinases. A list of uridine kinases was obtained with the NCBI BLAST tool using the AcP10 sequence as the query, with subsequent selection of sequences with at least $95 \%$ coverage. To obtain a list of representative sequences from all of the relevant phylogenetic groups, the resulting sequence list was manually supplemented with sequences from Animalia, Archaea, Bacteria and Mimiviridae. The total sequence list was aligned using the Multiple Sequence Comparison by Log-Expectation (MUSCLE) method. Subsequently, a phylogenetic tree was created in MEGA X software ${ }^{57}$ with the neighbour-joining method, using the number-of-differences substitutions model and a site coverage cut-off of $99 \%$. The final dataset included 173 positions from 300 amino acid sequences.

Statistics and reproducibility. All uridine kinase, immunofluorescence, flow cytometry, end-point dilution and western blot data shown in the figures originate from representative experiments of at least three biologically independent replicates. Quantifications of immunofluorescence images were done using at least three images originating from three biologically independent experiments containing more than ten cells each. The ${ }^{35} \mathrm{~S}$ radiolabelling data were based on two biologically independent experiments. The TAP mass spectrometry and cross-linking LC/MS were single experiments.

Reporting Summary. Further information on research design is available in the Nature Research Reporting Summary linked to this article.

\section{Data availability}

There are no restrictions on data availability. All relevant data are shown in the figures or are available in the extended data files, source data files or Supplementary Tables 1 and 2. The data that support the findings of this study are available from the corresponding author upon request. The AcP10 TAP mass spectrometry data have been deposited in the ProteomeXchange Consortium via the PRIDE partner repository with the dataset identifier PXD011879. Source data are provided with this paper.

Received: 27 May 2019; Accepted: 22 June 2020;

Published online: 20 July 2020

\section{References}

1. Pakos-Zebrucka, K. et al. The integrated stress response. EMBO Rep. 17, 1374-1395 (2016).

2. Levin, D. \& London, I. M. Regulation of protein synthesis: activation by double-stranded RNA of a protein kinase that phosphorylates eukaryotic initiation factor 2. Proc. Natl Acad. Sci. USA 75, 1121-1125 (1978).

3. Panniers, R. \& Henshaw, E. C. A GDP/GTP exchange factor essential for eukaryotic initiation factor 2 cycling in Ehrlich ascites tumor cells and its regulation by eukaryotic initiation factor 2 phosphorylation. J. Biol. Chem. 258, 7928-7934 (1983).

4. Rowlands, A. G., Panniers, R. \& Henshaw, E. C. The catalytic mechanism of guanine nucleotide exchange factor action and competitive inhibition by phosphorylated eukaryotic initiation factor 2. J. Biol. Chem. 263, 5526-5533 (1988)

5. Kulak, N. A., Pichler, G., Paron, I., Nagaraj, N. \& Mann, M. Minimal, encapsulated proteomic-sample processing applied to copy-number estimation in eukaryotic cells. Nat. Methods 11, 319-324 (2014).

6. Singh, C. R. et al. Change in nutritional status modulates the abundance of critical pre-initiation intermediate complexes during translation initiation in vivo. J. Mol. Biol. 370, 315-330 (2007).

7. Leroux, A. \& London, I. Regulation of protein synthesis by phosphorylation of eukaryotic initiation factor 2 alpha in intact reticulocytes and reticulocyte lysates. Proc. Natl Acad. Sci. USA 79, 2147-2151 (1982).

8. Lu, Y., Wambach, M., Katze, M. G. \& Krug, R. M. Binding of the influenza virus NS1 protein to double-stranded RNA inhibits the activation of the protein kinase that phosphorylates the eIF-2 translation initiation factor. Virology 214, 222-228 (1995).

9. Rabouw, H. H. et al. Middle East respiratory coronavirus accessory protein 4a inhibits PKR-mediated antiviral stress responses. PLoS Pathog. 12, e1005982 (2016).

10. Dar, A. C. \& Sicheri, F. X-ray crystal structure and functional analysis of vaccinia virus $\mathrm{K} 3 \mathrm{~L}$ reveals molecular determinants for PKR subversion and substrate recognition. Mol. Cell 10, 295-305 (2002).

11. Kawagishi-Kobayashi, M., Silverman, J. B., Ung, T. L. \& Dever, T. E. Regulation of the protein kinase PKR by the vaccinia virus pseudosubstrate inhibitor $\mathrm{K} 3 \mathrm{~L}$ is dependent on residues conserved between the $\mathrm{K} 3 \mathrm{~L}$ protein and the PKR substrate eIF2alpha. Mol. Cell. Biol. 17, 4146-4158 (1997).

12. Cruz, J. L. G. et al. Coronavirus gene 7 counteracts host defenses and modulates virus virulence. PLoS Pathog. 7, e1002090 (2011).

13. Li, Y. et al. ICP34.5 protein of herpes simplex virus facilitates the initiation of protein translation by bridging eukaryotic initiation factor $2 \alpha$ (eIF2 $\alpha$ ) and protein phosphatase 1. J. Biol. Chem. 286, 24785-24792 (2011).

14. Mihindukulasuriya, K. A., Wu, G., St. Leger, J., Nordhausen, R. W. \& Wang, D. Identification of a novel coronavirus from a beluga whale by using a panviral microarray. J. Virol. 82, 5084-5088 (2008).

15. Nejepinska, J., Malik, R., Moravec, M. \& Svoboda, P. Deep sequencing reveals complex spurious transcription from transiently transfected plasmids. PLoS ONE 7, e43283 (2012).

16. Nejepinska, J., Malik, R., Wagner, S. \& Svoboda, P. Reporters transiently transfected into mammalian cells are highly sensitive to translational repression induced by dsRNA expression. PLOS ONE 9, e87517 (2014). 
17. Hato, S. V. et al. The mengovirus leader protein blocks interferon- $\alpha / \beta$ gene transcription and inhibits activation of interferon regulatory factor 3. Cell. Microbiol. 9, 2921-2930 (2007).

18. Visser, L. J. et al. FMDV leader protease cleaves G3BP1 and G3BP2 and inhibits stress granule formation. J. Virol. 93, e00922-18 (2018).

19. Sidrauski, C. et al. Pharmacological dimerization and activation of the exchange factor eIF2B antagonizes the integrated stress response. eLife $\mathbf{4}$, e07314 (2015)

20. Sidrauski, C. et al. Pharmacological brake-release of mRNA translation enhances cognitive memory. eLife 2, e00498 (2013).

21. Zyryanova, A. F. et al. Binding of ISRIB reveals a regulatory site in the nucleotide exchange factor eIF2B. Science 359, 1533-1536 (2018).

22. Tsai, J. C. et al. Structure of the nucleotide exchange factor eIF2B reveals mechanism of memory-enhancing molecule. Science 359, eaaq0939 (2018).

23. Rabouw, H. H. et al. The small molecule ISRIB suppresses the integrated stress response within a defined window of activation. Proc. Natl Acad. Sci. USA 116, 2097-2102 (2019).

24. Harding, H. P. et al. Regulated translation initiation controls stress-induced gene expression in mammalian cells. Mol. Cell 6, 1099-1108 (2000).

25. Lu, P. D., Harding, H. P. \& Ron, D. Translation reinitiation at alternative open reading frames regulates gene expression in an integrated stress response. J. Cell Biol. 167, 27-33 (2004).

26. Vattem, K. M. \& Wek, R. C. Reinitiation involving upstream ORFs regulates ATF4 mRNA translation in mammalian cells. Proc. Natl Acad. Sci. USA 101, 11269-11274 (2004).

27. Choi, H. et al. Analyzing protein-protein interactions from affinity purification-mass spectrometry data with SAINT.Curr. Protoc. Bioinformatics 8, 8.15 (2012).

28. Mohammad-Qureshi, S. S. et al. Purification of FLAG-tagged eukaryotic initiation factor 2B complexes, subcomplexes, and fragments from Saccharomyces cerevisiae. Methods Enzymol. 431, 1-13 (2007).

29. Liu, F., Lössl, P., Scheltema, R., Viner, R. \& Heck, A. J. R. Optimized fragmentation schemes and data analysis strategies for proteome-wide cross-link identification. Nat. Commun. 8, 15473 (2017).

30. Sekine, Y. et al. Mutations in a translation initiation factor identify the target of a memory-enhancing compound. Science 348, 1027-1030 (2015).

31. Agol, V. I. \& Gmyl, A. P. Viral security proteins: counteracting host defences. Nat. Rev. Microbiol. 8, 867-878 (2010).

32. Kashiwagi, K. et al. Structural basis for eIF2B inhibition in integrated stress response. Science 364, 495-499 (2019).

33. Kenner, L. R. et al. eIF2B-catalyzed nucleotide exchange and phosphoregulation by the integrated stress response. Science $\mathbf{3 6 4}$, 491-495 (2019).

34. Bogorad, A. M., Lin, K. Y. \& Marintchev, A. Novel mechanisms of eIF2B action and regulation by eIF $2 \alpha$ phosphorylation. Nucleic Acids Res. 45, 11962-11979 (2017).

35. Kashiwagi, K. et al. Crystal structure of eukaryotic translation initiation factor 2B. Nature 531, 122-125 (2016).

36. Halliday, M. \& Mallucci, G. R. Review: modulating the unfolded protein response to prevent neurodegeneration and enhance memory. Neuropathol. Appl. Neurobiol. 41, 414-427 (2015).

37. Moreno, J. A. et al. Sustained translational repression by eIF $2 \alpha-\mathrm{P}$ mediates prion neurodegeneration. Nature 485, 507-511 (2012).

38. Wang, C. et al. Inhibiting the integrated stress response pathway prevents aberrant chondrocyte differentiation thereby alleviating chondrodysplasia. eLife 7, e37673 (2018).

39. Nguyen, H. G. et al. Development of a stress response therapy targeting aggressive prostate cancer. Sci. Transl. Med. 10, eaar2036 (2018).

40. Halliday, M. et al. Partial restoration of protein synthesis rates by the small molecule ISRIB prevents neurodegeneration without pancreatic toxicity. Cell Death Dis. 6, e1672 (2015).

41. Wong, Y. L. et al. The small molecule ISRIB rescues the stability and activity of vanishing white matter disease eIF2B mutant complexes. eLife 7, e32733 (2018).

42. Chou, A. et al. Inhibition of the integrated stress response reverses cognitive deficits after traumatic brain injury. Proc. Natl Acad. Sci. USA 114, E6420-E6426 (2017)

43. Armenta-Medina, D., Segovia, L. \& Perez-Rueda, E. Comparative genomics of nucleotide metabolism: a tour to the past of the three cellular domains of life. BMC Genomics 15, 800 (2014).

44. Belov, G. A., Fogg, M. H. \& Ehrenfeld, E. Poliovirus proteins induce membrane association of GTPase ADP-ribosylation factor. J. Virol. 79, 7207-7216 (2005).

45. Dorobantu, C. M. et al. Recruitment of PI4KIII to coxsackievirus B3 replication organelles is independent of ACBD3, GBF1, and Arf1. J. Virol. 88, 2725-2736 (2014).
46. Greninger, A. L., Knudsen, G. M., Betegon, M., Burlingame, A. L. \& DeRisi, J. L. The 3A protein from multiple picornaviruses utilizes the golgi adaptor protein ACBD3 to recruit PI4KIII. J. Virol. 86, 3605-3616 (2012).

47. De Jong, A. S. et al. Determinants for membrane association and permeabilization of the coxsackievirus $2 \mathrm{~B}$ protein and the identification of the Golgi complex as the target organelle. J. Biol. Chem. 278, 1012-1021 (2003)

48. Shevchenko, A., Wilm, M., Vorm, O. \& Mann, M. Mass spectrometric sequencing of proteins from silver-stained polyacrylamide gels. Anal. Chem 86, 650-658 (1996).

49. Cristobal, A. et al. In-house construction of a UHPLC system enabling the identification of over 4000 protein groups in a single analysis. Analyst 137, 3541-3548 (2012)

50. Käll, L., Canterbury, J. D., Weston, J., Noble, W. S. \& MacCoss, M. J. Semi-supervised learning for peptide identification from shotgun proteomics datasets. Nat. Methods 4, 923-925 (2007).

51. Mellacheruvu, D. et al. The CRAPome: a contaminant repository for affinity purification-mass spectrometry data. Nat. Methods 10, 730-736 (2013).

52. Vizcaíno, J. A. et al. The Proteomics Identifications (PRIDE) database and associated tools: status in 2013. Nucleic Acids Res. 41, D1063-D1069 (2013).

53. Šali, A. \& Blundell, T. L. Comparative protein modelling by satisfaction of spatial restraints. J. Mol. Biol. 234, 779-815 (1993).

54. Fiser, A., Do, R. K. G. \& Šali, A. Modeling of loops in protein structures. Protein Sci. 9, 1753-1773 (2000).

55. McWilliam, H. et al. Analysis Tool Web Services from the EMBL-EBI. Nucleic Acids Res. 41, W597-W600 (2013).

56. Shen, M. \& Sali, A. Statistical potential for assessment and prediction of protein structures. Protein Sci. 15, 2507-2524 (2006).

57. Kumar, S., Stecher, G., Li, M., Knyaz, C. \& Tamura, K. MEGA X: molecular evolutionary genetics analysis across computing platforms. Mol. Biol. Evol. 35, 1547-1549 (2018)

58. Suzuki, N. N., Koizumi, K., Fukushima, M., Matsuda, A. \& Inagaki, F. Structural basis for the specificity, catalysis, and regulation of human uridine-cytidine kinase. Structure 12, 751-764 (2004).

59. Schmidt, E. K., Clavarino, G., Ceppi, M. \& Pierre, P. SUnSET, a nonradioactive method to monitor protein synthesis. Nat. Methods $\mathbf{6}$ 275-277 (2009)

\section{Acknowledgements}

We thank A. Thomas and J. de Groot-Mijnes for critical reading of the manuscrip and helpful suggestions. We thank D. Ron for kindly providing HeLa cells stably expressing $3 \times$ FLAG-tagged eIF2B $\beta$, A. Greninger for the pAV AiV complementary DNA clone, G. Belov for HeLa R19 cells and J. Pelletier for the translation inhibitor pateamine A. The work was supported by the Netherlands Organisation for Scientific Research through a Vici grant (no. NWO-918.12.628) to F.J.M.v.K. and a Veni grant (no. NWO-863.13.008) to M.A.L. P.G., F.L. and A.J.R.H. acknowledge support from the Netherlands Organisation for Scientific Research funding the large-scale proteomics facility Proteins@Work (project 184.032.201) embedded in the Netherlands Proteomics Centre. Work in the laboratories of F.J.M.v.K. and A.J.R.H. is supported by the ULS Molecular Immunology Hub. P.W. is an Investigator of the Howard Hughes Medical Institute.

\section{Author contributions}

H.H.R., L.J.V., T.C.P., J.G.D., S.G.v.d.G., A.L.W.v.V. and J.G.S. performed the biochemical and virological assays. H.H.R., L.J.V., M.A.L., R.J.d.G. and F.J.M.v.K. conceptualized and analysed most of the experiments. F.L. and P.G. performed and analysed the mass spectrometry analyses. M.E.T. performed in silico modelling of protein structures. P.W. and A.A.A. generated biological reagents. H.H.R., R.J.d.G. and F.J.M.v.K. wrote the original manuscript draft. H.H.R., R.J.d.G., F.J.M.v.K., A.M.J.J.B., A.J.R.H. and P.W. revised and edited the manuscript. M.A.L., P.W., A.J.R.H., R.J.d.G., A.M.J.J.B. and F.J.M.v.K. supervised the project. M.A.L., P.W., A.J.R.H. and F.J.M.v.K. acquired funding.

\section{Competing interests}

The authors declare no competing interests.

\section{Additional information}

Extended data is available for this paper at https://doi.org/10.1038/s41564-020-0759-0.

Supplementary information is available for this paper at https://doi.org/10.1038/ s41564-020-0759-0.

Correspondence and requests for materials should be addressed to F.J.M.v.K.

Reprints and permissions information is available at www.nature.com/reprints.

Publisher's note Springer Nature remains neutral with regard to jurisdictional claims in published maps and institutional affiliations.

(c) The Author(s), under exclusive licence to Springer Nature Limited 2020 

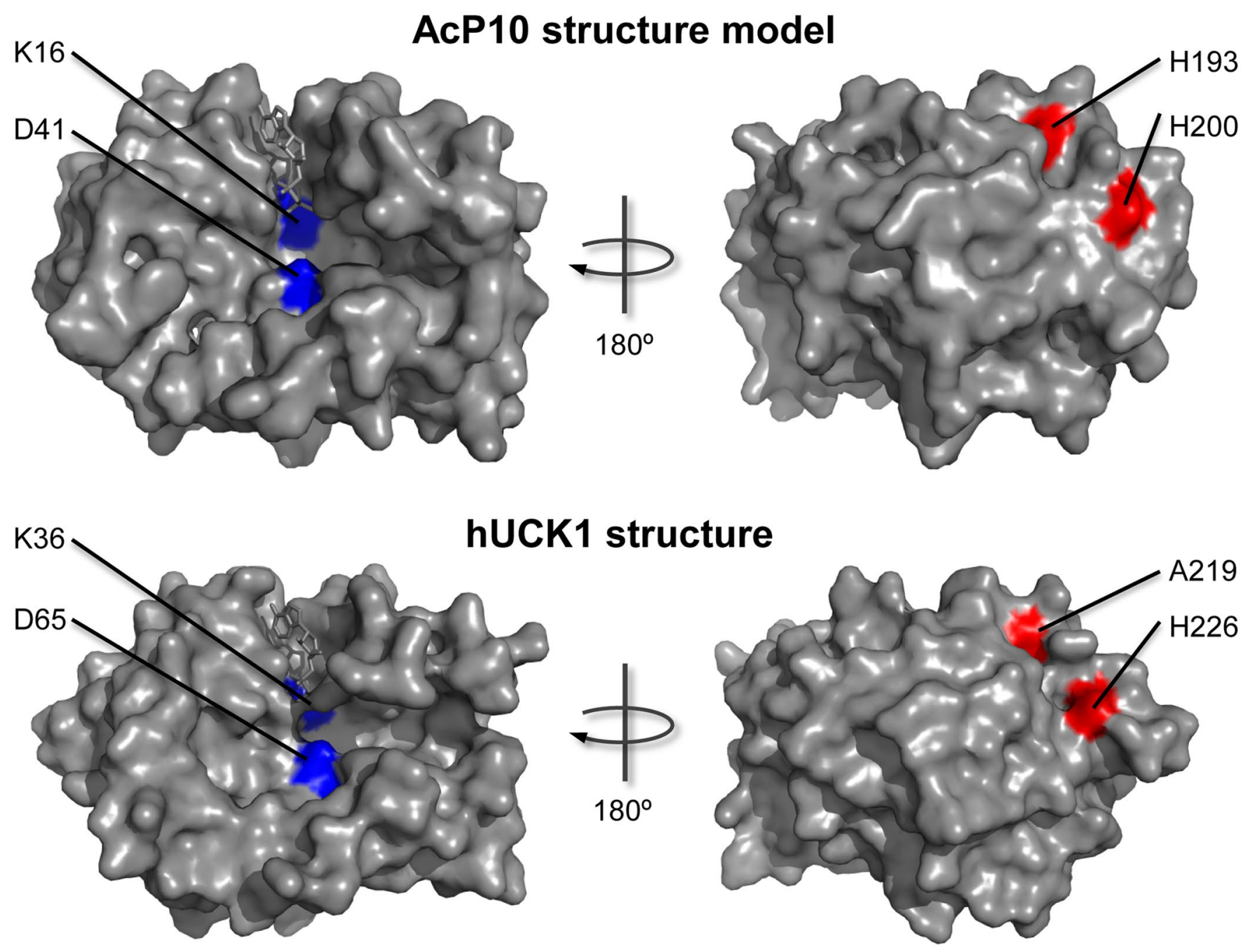

Extended Data Fig. 1| Structural modeling of AcP10. The AcP10 structure was modelled based on its homology to human uridine cytidine kinase 1 (hUCK1, accession number; pdb file 2UVQ). Indicated are the residues important for uridine kinase function (In blue; ATP binding site K16 and catalytic site D41), and those important for AcP10's ability to antagonize the ISR (In red; H193 and H200). 

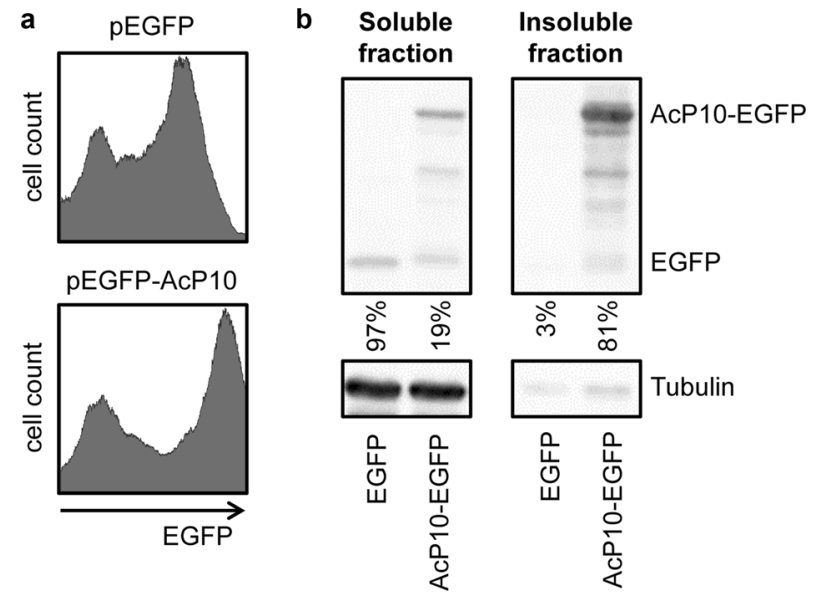

Extended Data Fig. 2 | AcP10 is highly insoluble. a, Flow cytometry analysis of EGFP expression levels in cells expressing EGFP (top panel) or the AcP10-EGFP fusion protein (bottom panel). b, Cells overexpressing AcP10-EGFP or EGFP were lysed in buffer containing $1 \%$ triton X100. The soluble fraction obtained after centrifugation, and the insoluble fraction obtained after resuspension of the cell debris in $8 \mathrm{M}$ urea, were analyzed by Western blot for presence of the overexpressed protein, using an antibody directed against EGFP. These experiments were performed three times independently with similar results. 


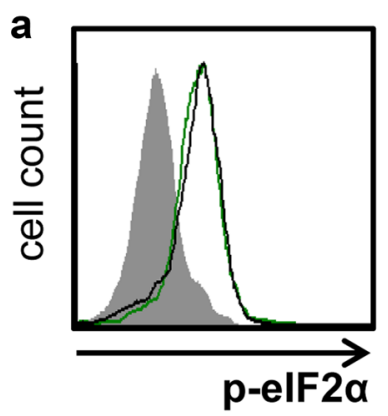

b

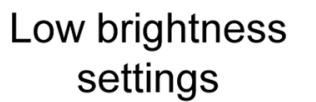
High brightness settings

C
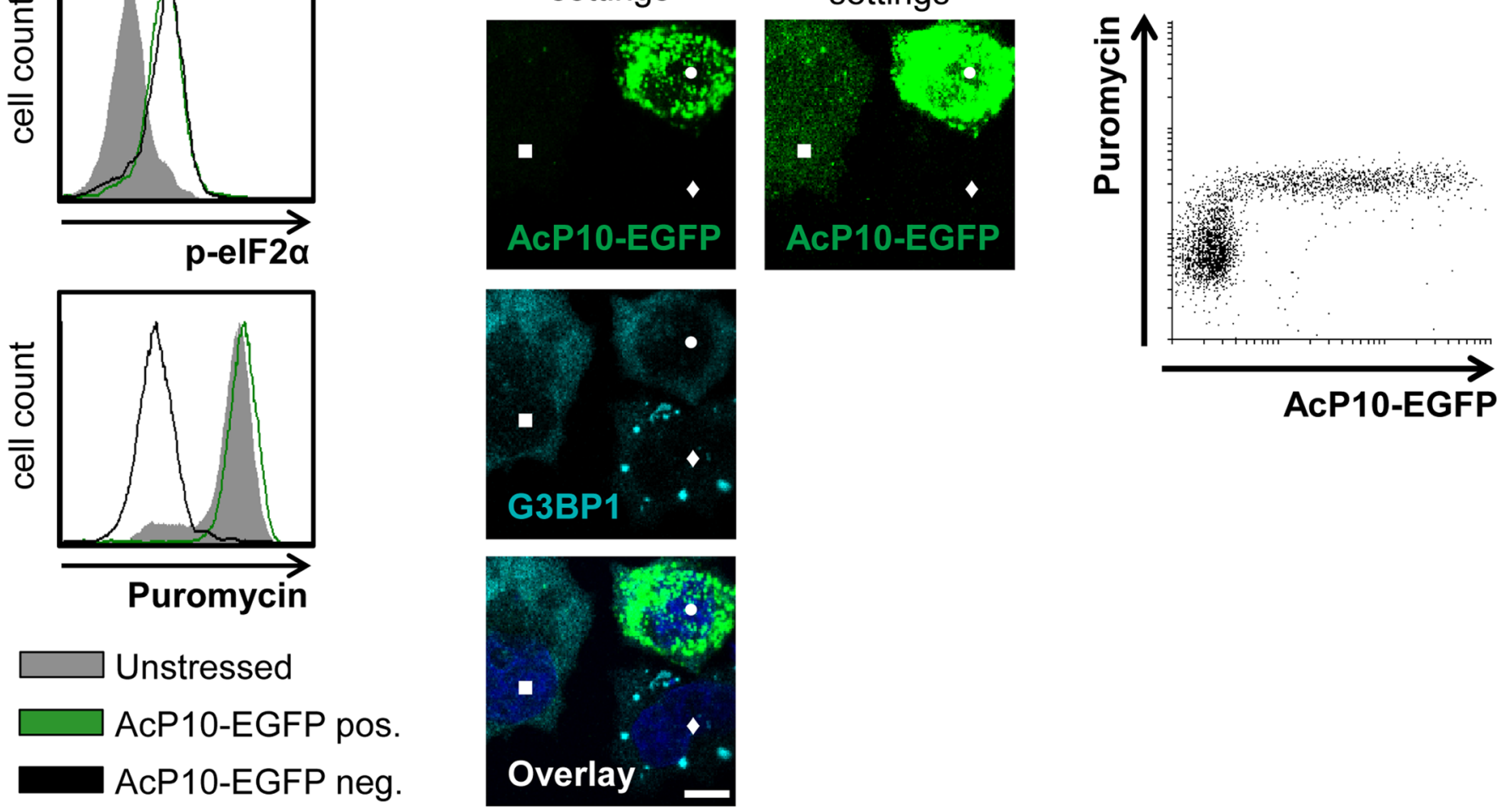

Extended Data Fig. 3 | Low levels of AcP10 are sufficient to fully rescue translation. a, Flow cytometry analysis of p-elF2 levels and ongoing translation in pEGFP-AcP10 transfected cells treated with arsenite for $30 \mathrm{~min}$. A mock treated sample is shown in grey fill. AcP10-positive cells are indicated in green, and AcP10-negative cells from the same well are shown in black. b. Immune fluorescence analysis of SG formation in pEGFP-AcP10 transfected cells treated with arsenite for $30 \mathrm{~min}$. Shown are three cells, one of which expresses AcP10 at relatively high levels ( $)$ ), one expresses AcP10 at low levels ( and one does not express AcP10 ( $)$. SG marker G3BP1 was visualized to assess SG formation. The white scale bar indicates $10 \mu \mathrm{m}$. c, Flow cytometry analysis of EGFP expression and ongoing translation in a pEGFP-AcP10 transfected cell population treated with arsenite for 30 min. These experiments were performed three times independently with similar results. 
EMCV-wt

Genes encoding structural proteins
Genes encoding non-structural proteins
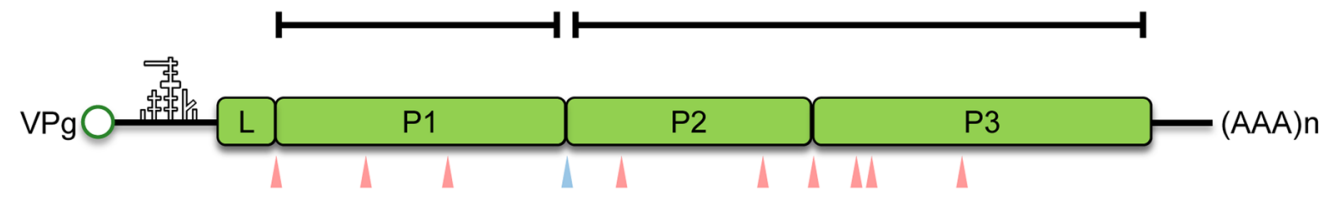

EMCV-LZn

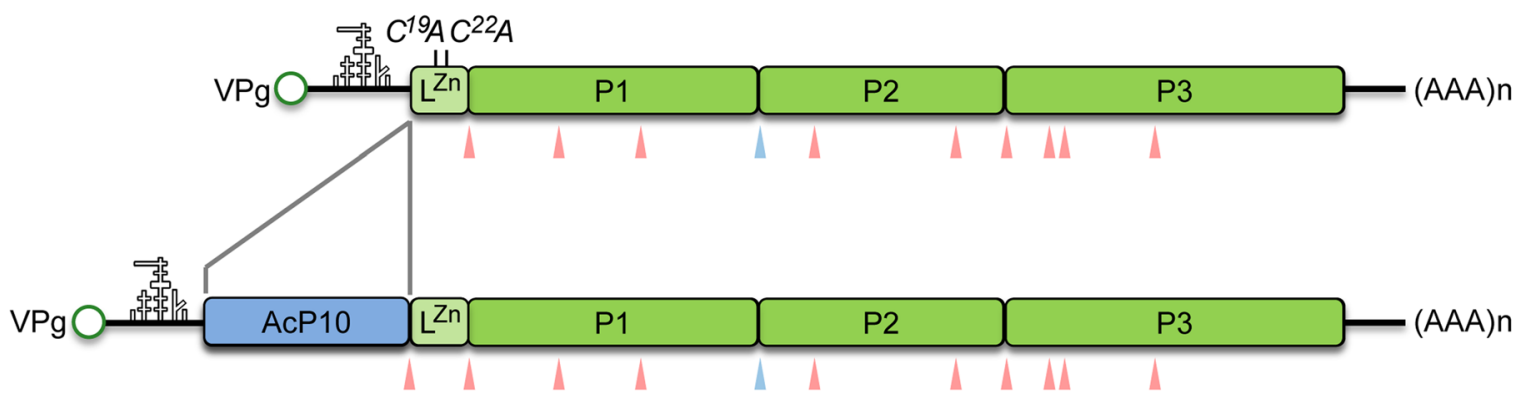

EMCV-LZn AcP10

\section{EMCV-LZn- AcP10(SA-)}

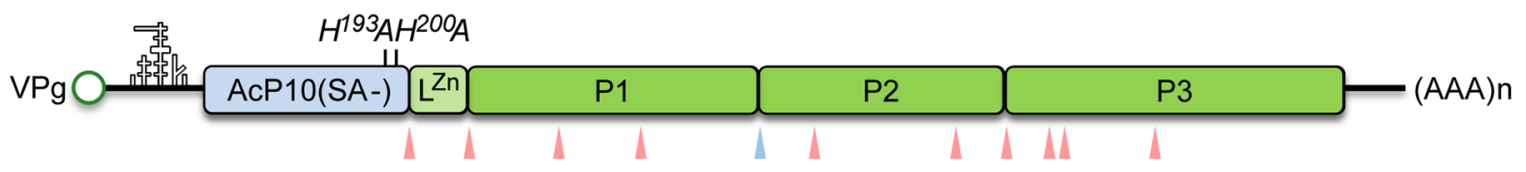

Extended Data Fig. 4 | Genome compositions of recombinant EMCVs used in this study. The EMCV genome consists of a 5' VPg viral protein, a 5' UTR which includes the EMCV IRES, a single ORF encoding the EMCV polyprotein, and a 3' UTR which includes a poly-A tail (top panel). In the EMCV-Lin virus, the endogenous ISR antagonist ( $L$ ) is inactivated by a double point mutation (second panel). The genes encoding AcP10 or AcP10(SA-) were inserted into the EMCV-L2n genome to obtain EMCV-L2n-ACP10 and EMCV-L2n-AcP10(SA-), respectively. (bottom two panels). The viral proteins are separated from the polyprotein by a $2 \mathrm{~A}$ skip site (indicated by the blue arrowhead), or through catalytic activity of the $3 \mathrm{C}$ viral protease (cleavage sites indicated by red arrowheads). 

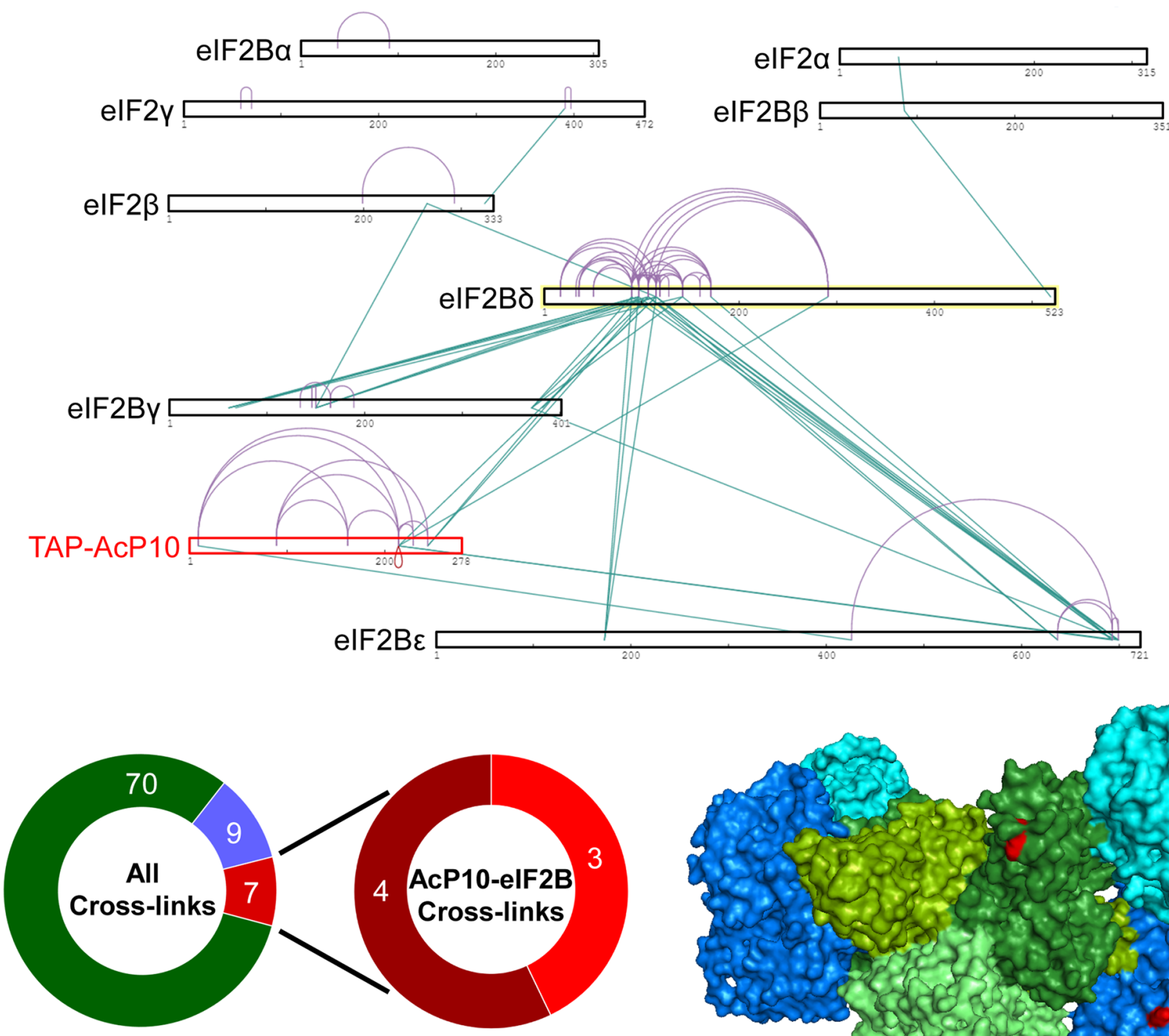

elF2B-elF2B
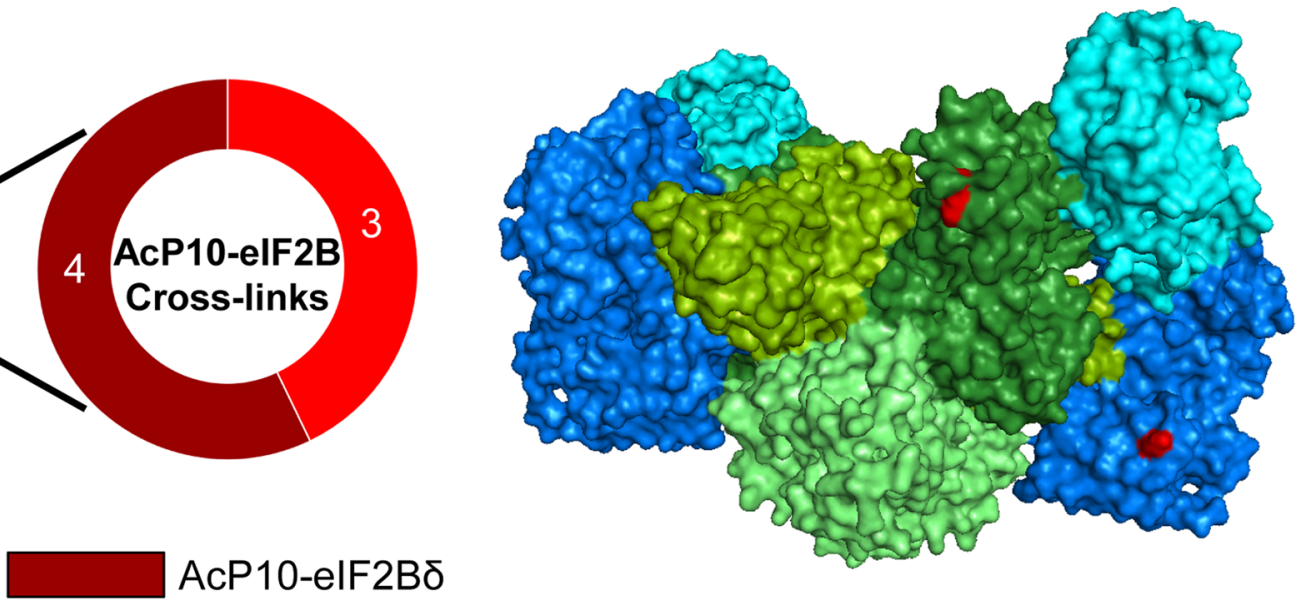

AcP10-AcP10

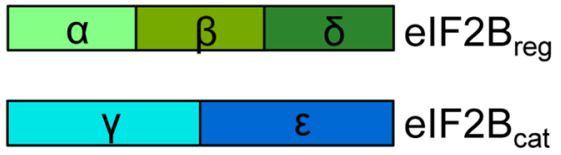

\section{AcP10-elF2B}

AcP10-elF2B $\varepsilon$

Extended Data Fig. 5 | Cross-linking mass-spectrometry analysis of AcP10•elF2B•elF2 complexes. a, Schematic overview of the cross-links identified in AcP10-elF2B-elF2 complexes that were affinity purified using TAP-AcP10. Indicated in teal are inter-protein cross-links and indicated in purple are intra-protein cross-links. A single cross-link was formed between two of the same peptides from AcP10 (indicated in red), which may have occurred due to AcP10's tendency to aggregate. b, Schematic overview of the total number of cross-links found within AcP10 (blue), within the elF2B complex (green), and between $A c P 10$ and elF2B subunits (red). If present in resolved parts of elF2B, the elF2B residues that cross-linked with $A c P 10$ are indicated in red in the right panel. The subunits of the elF2B regulatory subcomplex (elF2 $\mathrm{B}_{\text {reg }}$ ) and elF2B catalytic subcomplex (elF2 $\mathrm{B}_{\text {cat }}$ ) are shown in shades of green or blue, respectively, as indicated. 
a
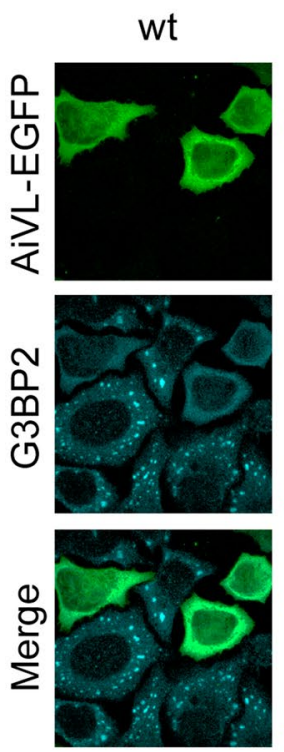

$C^{53} \mathrm{~A}$
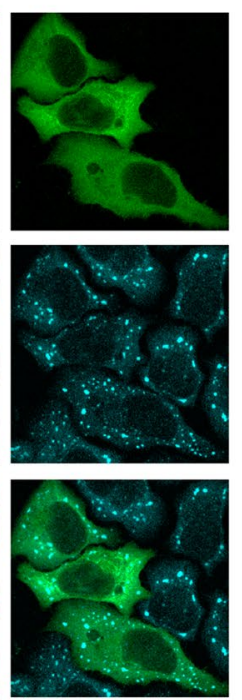

\section{$\mathrm{C}^{56} \mathrm{~A}$}
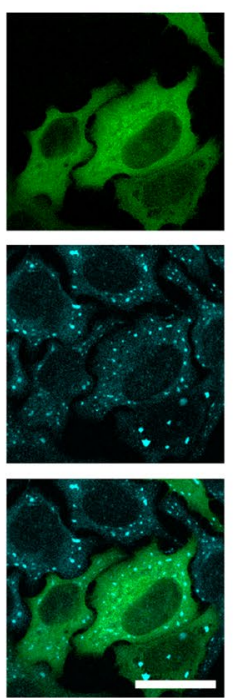

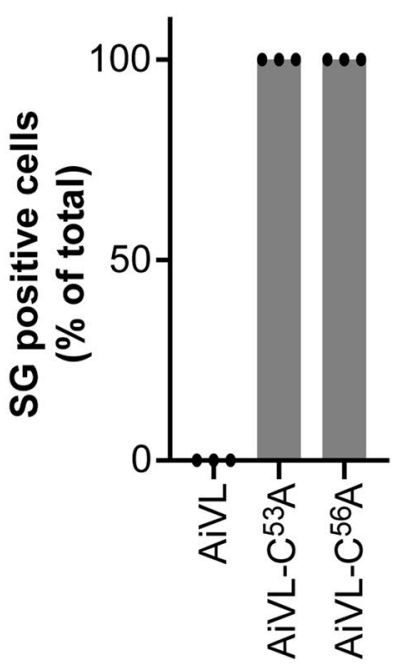

b
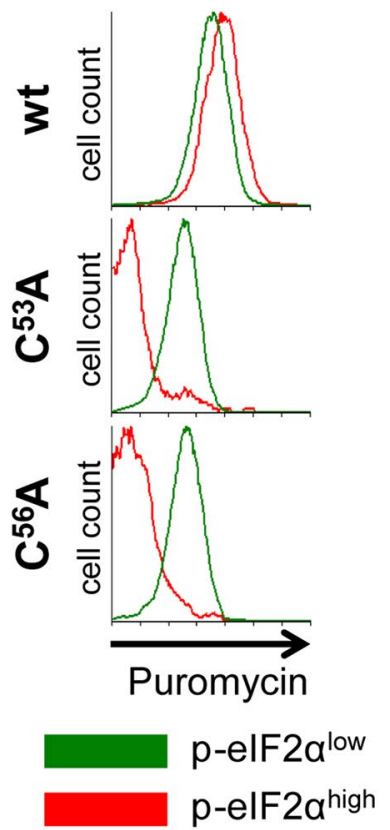

C

Cell lysates
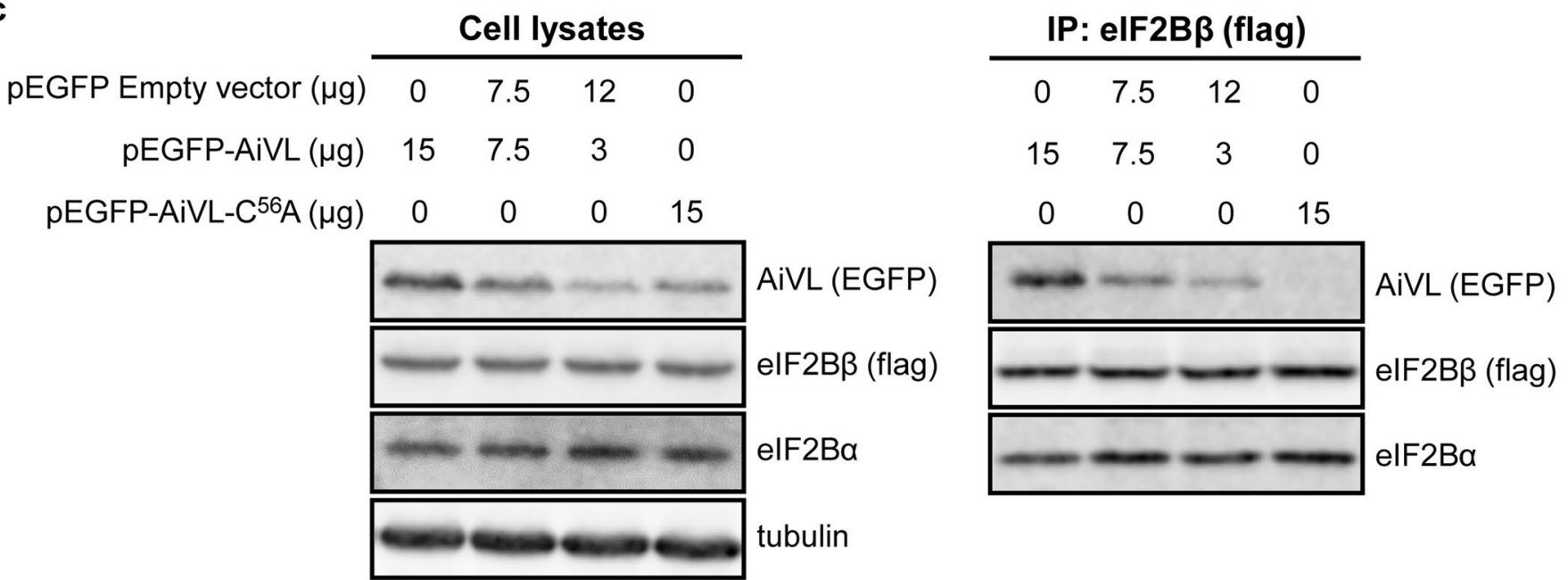

Extended Data Fig. 6 | Knockout of the ISR inhibition function of AiVL by mutations C53A and C56A. a, IFA analysis of SG formation in HeLa cells transiently overexpressing the indicated EGFP-AiVL fusion proteins. Before fixation, cells were treated with $500 \mu \mathrm{M}$ arsenite for 45 min. Quantifications of the percentage of SG positive cells are given in the bar graph in the right panel. Mean $\pm S D$ of $n=3$ biologically independent experiments are shown. The white scale bar indicates $50 \mu \mathrm{m}$. b. Flow cytometry analysis of active translation, as labeled by puromycin incorporation, in cells transiently transfected with plasmids encoding the indicated AiVL proteins. Only transfected cells (EGFPpos) are shown, and cells were further subdivided in p-elF2 $\alpha^{\text {low }}$ (green) and p-elF $2 \alpha^{\text {high }}$ (red) cells, as shown in Fig. 6b. c, The indicated plasmids were transiently transfected in HeLa-elF2B $\beta$-3xflag cells. The next day, elF2B was isolated from cell lysates, and co-purified EGFP-tagged AiVL or AiVL-C56A was analysed by Western blotting using an antibody directed against EGFP.

These experiments were performed three times independently with similar results. 

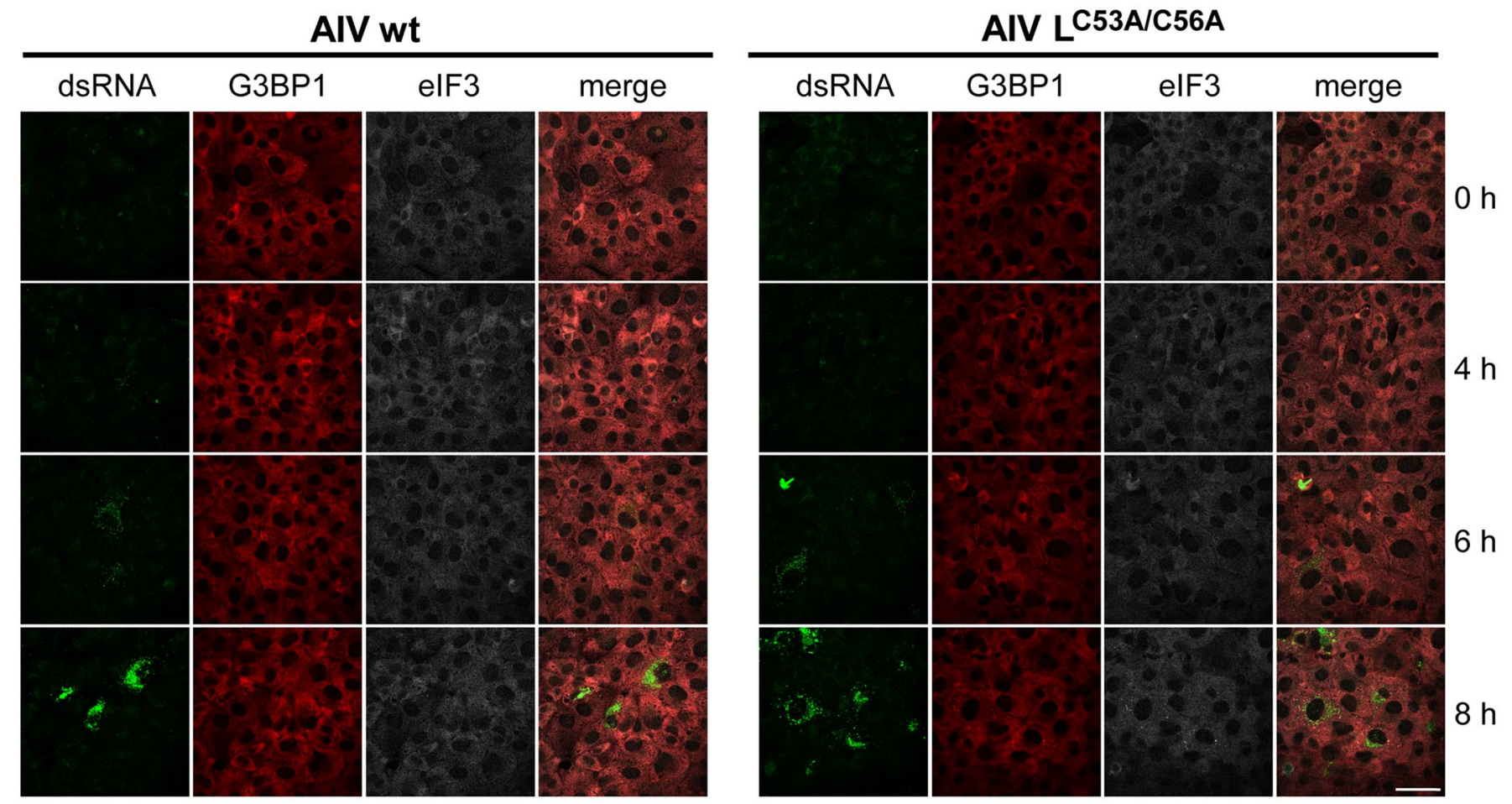

Extended Data Fig. 7 | SG formation over time in cells infected with AiV wt or AiV-L ${ }^{\text {C53A/C56A. }}$. Vero cells were infected $(\mathrm{MOI}=0.1)$ with AiV wt or $\mathrm{AiV}-\mathrm{L}^{\mathrm{C} 53 \mathrm{~A} / \mathrm{C} 56 \mathrm{~A}}$. At the indicated time points p.i. cells were fixed and the presence of $\mathrm{SG}$ in infected cells was assessed by immunofluorescence using antibodies directed against dsRNA, G3BP1, and elF3. The white scale bar indicates $50 \mu \mathrm{m}$. This experiment was performed twice independently with similar results. 


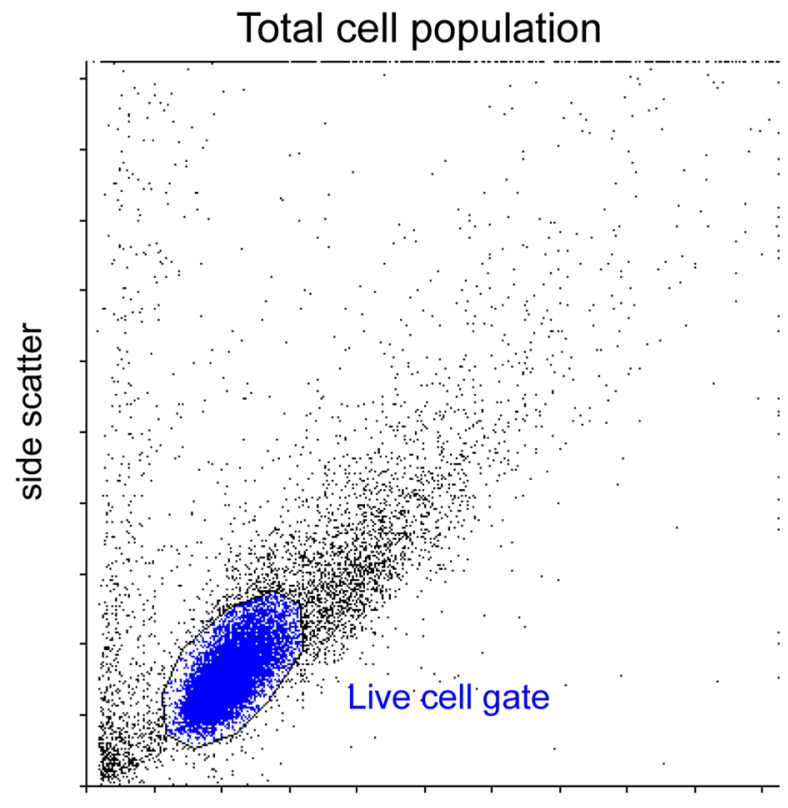

forward scatter

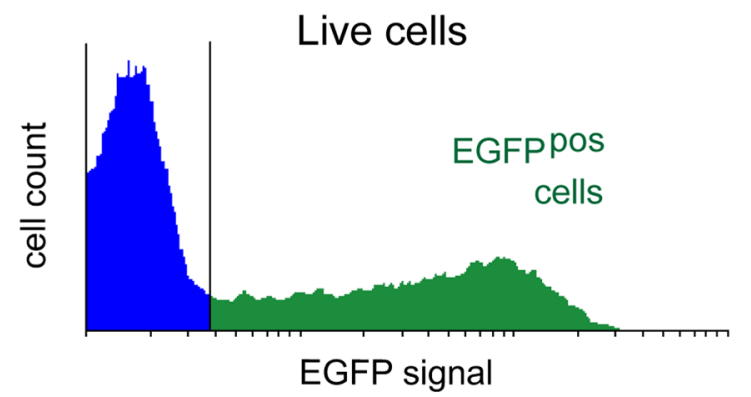

Extended Data Fig. 8 | Gating strategy used for flow cytometry analyses. For all flow cytometry samples, live cells were identified based on FSC/SSC profile (top panel). When indicated, transfected cells within the live cell population were selected based on EGFP expression (bottom panel). 


\section{Reporting Summary}

Nature Research wishes to improve the reproducibility of the work that we publish. This form provides structure for consistency and transparency in reporting. For further information on Nature Research policies, see Authors \& Referees and the Editorial Policy Checklist.

\section{Statistics}

For all statistical analyses, confirm that the following items are present in the figure legend, table legend, main text, or Methods section.

$\mathrm{n} / \mathrm{a}$ | Confirmed

$\square$ \.he exact sample size $(n)$ for each experimental group/condition, given as a discrete number and unit of measurement

$\square$ \ A statement on whether measurements were taken from distinct samples or whether the same sample was measured repeatedly

$\square$ The statistical test(s) used AND whether they are one- or two-sided

$\square$ Only common tests should be described solely by name; describe more complex techniques in the Methods section.

$\bigotimes \square$ A description of all covariates tested

Х $\square$ A description of any assumptions or corrections, such as tests of normality and adjustment for multiple comparisons

$\square$ A full description of the statistical parameters including central tendency (e.g. means) or other basic estimates (e.g. regression coefficient)

AND variation (e.g. standard deviation) or associated estimates of uncertainty (e.g. confidence intervals)

$\triangle$ For null hypothesis testing, the test statistic (e.g. $F, t, r$ ) with confidence intervals, effect sizes, degrees of freedom and $P$ value noted

$\triangle \square$ Give $P$ values as exact values whenever suitable.

Х $\square$ For Bayesian analysis, information on the choice of priors and Markov chain Monte Carlo settings

Х $\square$ For hierarchical and complex designs, identification of the appropriate level for tests and full reporting of outcomes

Х $\square$ Estimates of effect sizes (e.g. Cohen's $d$, Pearson's $r$ ), indicating how they were calculated

Our web collection on statistics for biologists contains articles on many of the points above.

\section{Software and code}

Policy information about availability of computer code

Data collection

LAS-AF, version 3.2, Leica

https://www.leica-microsystems.com/

FACSdiva v6.1.3 BD, bioscience

http://www.bdbiosciences.com/us/instruments/clinical/software/flow-cytometry-acquisition/bd-facsdiva-software/m/333333/overview

Proteome discoverer, version 2.1, Thermo Scientific

https://www.thermofisher.com/order/catalog/product/OPTON-30795

Mascot, version 2.5.1, Matrix Science

http://www.matrixscience.com/

Modeller, version 9.12, University of California, San Francisco

https://salilab.org/modeller/

Data analysis

EMBOSS Needle, EMBL-EBI

https://www.ebi.ac.uk/Tools/psa/emboss_needle/

Cyflogic, version 1.2.1, CyFlo Ltd.

http://www.cyflogic.com/

ImageJ, version $1.51 \mathrm{t}, \mathrm{NIH}$

https://fiji.sc/ 


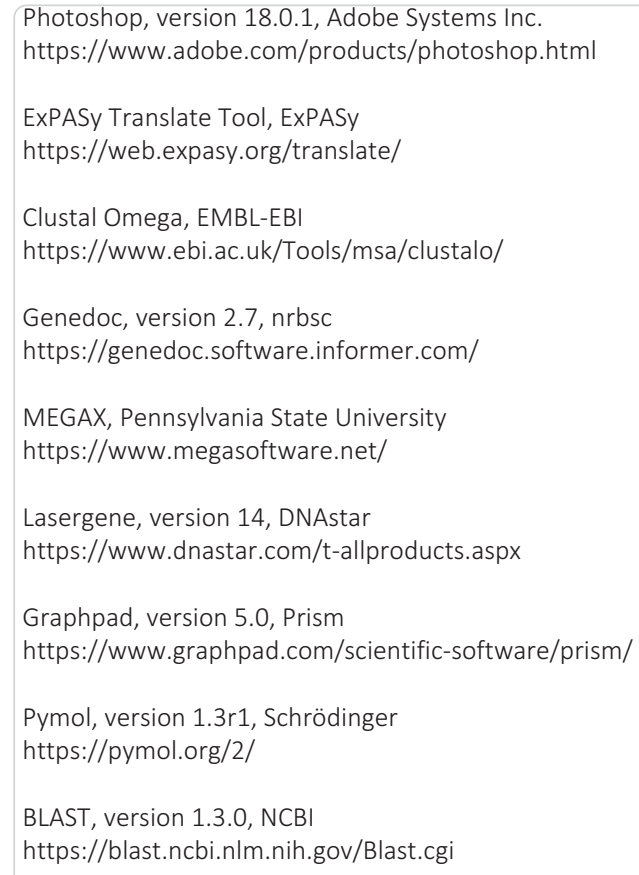

\section{Data}

Policy information about availability of data

All manuscripts must include a data availability statement. This statement should provide the following information, where applicable:

- Accession codes, unique identifiers, or web links for publicly available datasets

- A list of figures that have associated raw data

- A description of any restrictions on data availability

There are no restrictions on data availability. All relevant data are shown in the figures, or available in the supplementary datasets 1 -3. The AcP10 tandem affinity purification mass spectrometry data have been deposited in the ProteomeXchange Consortium via the PRIDE partner repository with the dataset identifier PXD011879.

\section{Field-specific reporting}

Please select the one below that is the best fit for your research. If you are not sure, read the appropriate sections before making your selection. $\bigotimes$ Life sciences $\quad \square$ Behavioural \& social sciences $\quad \square$ Ecological, evolutionary \& environmental sciences

\section{Life sciences study design}

All studies must disclose on these points even when the disclosure is negative.

Sample size

Data exclusions

Replication

Randomization

Blinding
For flow cytometry experiments, at least 10.000 cells/sample were analysed.

Mass Spectrometry analysis of AcP10 interaction partners was done only once. Since the elF2 and elF2B complexes were identified with high confidence, and since the identifcation of all their subunits ( 8 in total) served as independent cross-confirmation, this experiment identified elF2/elF2B as interaction partner of AcP10 in a satisfactory manner. These data were then confirmed independently by Western blot analyses in multiple biologically independent experiments $(n=3)$. All experiments shown were performed at least 3 times independently unless clearly stated otherwise. For all data shown, the results of independent biological replicates were consistent with eachother.

No data was excluded

All data reported in this study was reproduced at least twice, as well as (when possible) via alternative independent methods. Throughout this study, no data were obtained that contradicted previously obtained data

To allow accurate comparison between the data presented in the figures, the substrates that were used for each figure were grouped and the data was obtained at the same day. Randomization is not applicable in this case.

Blinding was for most experiments not relevant as the reported data is mostly based not on subjective observations, but quantitative 


\section{Reporting for specific materials, systems and methods}

We require information from authors about some types of materials, experimental systems and methods used in many studies. Here, indicate whether each material, system or method listed is relevant to your study. If you are not sure if a list item applies to your research, read the appropriate section before selecting a response.

\begin{tabular}{l|l} 
Materials \& experimental syste \\
\hline $\mathrm{n} / \mathrm{a}$ & Involved in the study \\
\hline & $\bigotimes$ Antibodies \\
$\square$ & $\square$ Eukaryotic cell lines \\
$\square$ & Palaeontology \\
$\square$ & Animals and other organisms \\
$\square$ Clinical data
\end{tabular}

\begin{tabular}{l|l}
\multicolumn{2}{l}{ Methods } \\
\hline n/a & Involved in the study \\
$\square$ & $\square$ ChIP-seq \\
$\square$ & $\square$ Flow cytometry \\
$\square$ & $\square$ MRI-based neuroimaging
\end{tabular}

\section{Antibodies}

a-G3BP1, clone 23, BD Biosciences Cat\# 611127, 1:200 (Immunofluorescence) RRID:AB_398438

a-Puromycin, clone 12D10, Merck Millipore Cat\# MABE343, 1:100 (flow cytometry) 1:1000 (Western blot) RRID:AB 2566826

$\alpha$-p-elF2 $\alpha$, clone E90, Abcam Cat\# ab32157, 1:100 (flow cytometry) 1:1000 (Western blot)

RRID:AB_732117

$\alpha$-elF2 $\alpha$, polyclonal, Cell Signaling Cat\# 9722, 1:1000 (Western blot)

RRID:AB_2230924

$\alpha$-EGFP, polyclonal, Prof. J Fransen (De Jong et al., 2003), 1:1000 (Western blot)

$\alpha$-Tubulin, clone DM1A, Sigma-Aldrich Cat\# T9026, 1:1000 (Western blot)

RRID:AB 477593

a-dsRNA, clone J2, English\&Scientific consulting, 1:1000 (Immunofluorescence)

RRID:AB_2651015

$\alpha$-elF3n, clone N-20, SantaCruz Cat\# sc-16377, 1:200 (Immunofluorescence)

RRID:AB 671941

$\alpha$-Flag, clone M2, Sigma-Aldrich Cat\# F3165, 1:1000 (Western blot)

RRID:AB_259529

$\alpha$-elF2BE, polyclonal, Abcam Cat\# ab32713, 1:1000 (Western blot)

RRID:AB_2230901

$\alpha$-elF2B $\alpha$, polyclonal, Protein Tech Cat\# 18010-1-AP, 1:1000 (Western blot)

RRID:AB_2261996

goat $\alpha$-Mouse IRDye680, polyclonal, LI-COR Cat\# 926-68070, 1:15,000 (Western blot)

RRID:AB_10956588

goat $\alpha$-Rabbit IRDye800, polyclonal, LI-COR Cat\# 926-32211, 1:15,000 (Western blot)

RRID:AB_621843

donkey $\alpha$-Mouse Alexa488, polyclonal, Thermo Fisher Scientific Cat\# A-21202, 1:200 (Immunofluorescence)

RRID:AB_141607

donkey a-Goat Alexa568, polyclonal, Thermo Fisher Scientific Cat\# A-11058, 1:200 (Immunofluorescence)

RRID:AB_2534105

donkey $\alpha$-Rabbit Alexa647, polyclonal, Thermo Fisher Scientific Cat\# A-31573, 1:200 (Immunofluorescence) RRID:AB_2536183

donkey $\alpha$-Mouse cy5, polyclonal, Jackson ImmunoResearch Cat\# 715-175-150, 1:200 (flow cytometry) 1:200

(Immunofluorescence)

RRID:AB_2340819

goat $\alpha$-Rabbit Alexa594, polyclonal, Invitrogen Cat\# A-11012, 1:200 (flow cytometry)

RRID:AB_2534079

rabbit- $\alpha-G 3 B P 2$, polyclonal, Bethyl Laboratories Cat\# A302-040A, 1:200 (Immunofluorescence)

RRID:AB_1576545

Validation

a-G3BP1, clone 23, BD Biosciences Cat\# 611127:

See product page, antibody was used for immunofluorescence on A431 cells (Human epithelial carcinoma; ATCC CRL-1555) a-Puromycin, clone 12D10, Merck Millipore Cat\# MABE343

See product page, antibody can be used for multiple applications including flow cytometry and Western blotting; example publications: Reineke, L. C., et al. (2012). Mol Biol Cell. 23(18):3499-3510 and David, A., et al. (2012). J Cell Biol. 197(1):45-57. $\alpha$-p-elF2 $\alpha$, clone E90, Abcam Cat\# ab32157

See product page, antibody can be used for multiple applications including flow cytometry and Western blotting; example publication: Cagnetta R et al. (2012). Mol Cell. 73:474-489.e5

$\alpha$-elF2 $\alpha$, polyclonal, Cell Signaling Cat\# 9722

See product page, antibody can be used for multiple applications including Western blotting; example publication: Patra $U$, 
Mukhopadhyay U, Mukherjee A, Sarkar R, Chawla-Sarkar M. (2020) Oxid Med Cell Longev. 2020:7289120.

$\alpha$-EGFP, polyclonal, Prof. Fransen

This antibody is not commercially available, but was previously used for Western blotting by de Jong AS, Wessels E, Dijkman HB, et al. (2003) J Biol Chem. 278(2):1012-1021.

$\alpha$-Tubulin, clone DM1A, Sigma-Aldrich Cat\# T9026

See product page, antibody can be used to detect tubulin from numerous cell lines by Western blotting. Example publication: Adachi H, Waza M, Tokui K, et al. (2007) J Neurosci. 27(19):5115-5126.

a-dsRNA, clone J2, English\&Scientific consulting

See product page, this antibody is the gold standard when it comes to dsRNA detection and can be used for several assays,

including immunofluorescence. Example publication: Welsch S, Miller S, Romero-Brey I, et al. (2009) Cell Host Microbe. 5(4):365375.

$\alpha$-elF3n, clone N-20, SantaCruz Cat\# sc-16377

See product page, antibody can be used for multiple applications including immunofluorescence. Example publication: Sahoo MR, Gaikwad S, Khuperkar D, et al. (2017) EMBO Rep. 18(2):241-263.

$\alpha$-Flag, clone M2, Sigma-Aldrich Cat\# F3165

See product page, antibody can be used for multiple applications including Western blotting. Example publication: Dobrikova E,

Shveygert M, Walters R, Gromeier M. (2010) J Virol. 84(1):270-279.

$\alpha$-elF2B $\varepsilon$, polyclonal, Abcam Cat\# ab32713

See product page, antibody can be used for multiple applications including Western blotting. Example publication:

Cagnetta R, Wong HH, Frese CK, Mallucci GR, Krijgsveld J, Holt CE. (2019) Mol Cell. 73(3):474-489.e5.

$\alpha$-elF2B $\alpha$, polyclonal, Protein Tech Cat\# 18010-1-AP

See product page, antibody was used for Western blotting using HeLa cells, K-562 cells and MCF-7 cells.

goat $\alpha$-Mouse IRDye680, polyclonal, LI-COR Cat\# 926-68070

This antibody has been specifically tested and qualified for Western blot and In-Cell Western assay applications, as stated by the manufacterer.

goat $\alpha$-Rabbit IRDye800, polyclonal, LI-COR Cat\# 926-32211

This antibody has been specifically tested and qualified for Western blot and In-Cell Western assay applications, as stated by the manufacterer.

donkey $\alpha$-Mouse Alexa488, polyclonal, Thermo Fisher Scientific Cat\# A-21202

See product page, antibody can be used for multiple applications including immunofluorescence. Example publication: Trinidad EM, Ballesteros M, Zuloaga J, Zapata A, Alonso-Colmenar LM. (2019) Blood. 114(24):5081-5090.

donkey a-Goat Alexa568, polyclonal, Thermo Fisher Scientific Cat\# A-11058

See product page, antibody can be used for multiple applications including immunofluorescence. Example publication: Zhao $\mathrm{C}$, Chen A, Jamieson CH, et al. (2009) Nature. 458(7239):776-779.

donkey $\alpha$-Rabbit Alexa647, polyclonal, Thermo Fisher Scientific Cat\# A-31573

See product page, antibody can be used for multiple applications including immunofluorescence. Example publication: Sacchi S, Bernasconi M, Martineau M, et al. (2008) J Biol Chem. 283(32):22244-22256.

donkey $\alpha$-Mouse cy5, polyclonal, Jackson ImmunoResearch Cat\# 715-175-150

See product page, antibody can be used for multiple applications including immunofluorescence and flow cytometry. Example publication: Heinz KS, Rapp A, Casas-Delucchi CS, et al. (2009) Epigenetics Chromatin. 12(1):18.

goat $\alpha$-Rabbit Alexa594, polyclonal, Invitrogen Cat\# A-11012

See product page, antibody can be used for multiple applications including immunofluorescence. Examples are shown on the product page.

rabbit- $\alpha-G 3 B P 2$, polyclonal, Bethyl Laboratories Cat\# A302-040A

See product page, antibody can be used for multiple applications including immunofluorescence. Example publication: Visser $\mathrm{L}$, Medina GN, Rabouw HH, et al. (2009) J Virol. 93(2):e00922-18.

\section{Eukaryotic cell lines}

Policy information about cell lines

Cell line source(s)

Human: HeLa-R19 Prof. G. Belov (Belov et al., 2005; Dorobantu et al., 2014)

Human: HeLa-R19-eIF2Bß-3xFLAG Prof. D. Ron (Sekine et al., 2015)

Human: HeLa-R19-PKRKO (Rabouw et al., 2016)

Hamster: BHK-21 ATCC ${ }^{\circledR}$ No. CCL-10 ${ }^{\text {TM }}$ RRID:CVCL 1915

Human: HEK293T ATCC ${ }^{\circledR}$ No. CRL-3216 ${ }^{\mathrm{TM}}$ RRID:CVCL_0063

African Green Monkey: Vero-E6 ATCC ${ }^{\circledR}$ No. CRL-1586 ${ }^{\mathrm{TM}}$ RRID:CVCL_0574

Authentication

The cell lines used were not authenticated. Cell lines originating from ATCC were extensively validated by ATCC.

Mycoplasma contamination

All cell lines used were tested for mycoplasma and found to be uncontaminated

Commonly misidentified lines

(See ICLAC register)

No commonly misidentified cell lines used 


\title{
Plots
}

Confirm that:

The axis labels state the marker and fluorochrome used (e.g. CD4-FITC).

\The axis scales are clearly visible. Include numbers along axes only for bottom left plot of group (a 'group' is an analysis of identical markers).

All plots are contour plots with outliers or pseudocolor plots.

A numerical value for number of cells or percentage (with statistics) is provided.

\section{Methodology}

Sample preparation

\begin{abstract}
HeLa cells were seeded on glass cover slips in a 24-wells cluster at sub confluent densities. Next day, cell layers were transfected with $500 \mathrm{ng}$ of the indicated plasmids using FUGENE 6 reagent according to manufacturer's protocol. After overnight incubation, cells were treated with $500 \mu \mathrm{M}$ arsenite or left untreated. Alternatively, cells were infected with the indicated viruses for $5 \mathrm{~h}$ (for EMCV) or $8 \mathrm{~h}$ (for AiV). Puromycin labeling of active translation was done by exposing cells to $20 \mathrm{\mu g} / \mathrm{ml}$ puromycin during the final 15 min of the assay. Cells layers were then released by trypsin treatment and fixed in 4\% PFA in PBS. Cells were permeabilized in ice-cold MeOH for 10 min. The samples were washed twice in FACS buffer (PBS + 1\% BSA) and subsequently incubated with primary antibodies mouse anti-Puromycin (Merck Millipore) and rabbit anti-p-elF2 $\alpha$ (Abcam) at 1:100 dilution in FACS buffer for $45 \mathrm{~min}$. Samples were washed twice in FACS buffer and subsequently incubated in secondary antibodies donkey anti-Mouse Cy5 (Jackson lab) and goat anti-Rabbit Alexa594 (Invitrogen) at 1:200 dilution in FACS buffer for 45 min. Samples were washed once in FACS buffer and kept in FACS buffer $+2 \%$ PFA at $4^{\circ} \mathrm{C}$ until analysis at the FACS Canto II (BD Biosciences)
\end{abstract}

Instrument

Software

Cell population abundance

Gating strategy

\section{BD FACS Canto}

FACSdiva v6.1.3

BD bioscience

Cyflogic, version 1.2.1

CyFlo Ltd.

N/A

All flow cytometry samples were first gated for the live-cell population based on FSC/SSC profile. All subsequent gating events (where applicable) are indicated in the figures, except for Fig 6B, in which case the cells were first further gated on EGFP signal (EGFPpos) similar to the analysis shown in Fig 6F.

$\bigotimes$ Tick this box to confirm that a figure exemplifying the gating strategy is provided in the Supplementary Information. 